\title{
Survival of Plants During Short-Term Boa-Oh Exposure: Ros Related Gene Expression and Detoxification Reactions are Accompaniedwithfast Membrane Lipid Repair in Root Tips
}

\section{Margot Schulz( $\sim$ ulp509@uni-bonn.de)}

University of Bonn: Rheinische Friedrich-Wilhelms-Universitat Bonn https://orcid.org/0000-0001-7373306X

\section{LAURA LASCHKE}

University of Bonn: Rheinische Friedrich-Wilhelms-Universitat Bonn

\section{VADIM SCHÜTZ}

Universität Bonn: Rheinische Friedrich-Wilhelms-Universitat Bonn

\section{OLIVER SCHACKOW}

Leipzig University: Universitat Leipzig

\section{DIETER SICKER}

Universität Leipzig: Universitat Leipzig

\section{DIANA HOFMANN}

Forschungszentrum Julich ICG: Forschungszentrum Julich GmbH

\section{PETER DÖRMANN}

Universität Bonn: Rheinische Friedrich-Wilhelms-Universitat Bonn

\section{Research Article}

Keywords: $\mathrm{BOA}-\mathrm{OH}$ isomers, ROS, detoxification, FAD2-2,SOD2, Lipids, membrane repair

Posted Date: July 2nd, 2021

DOl: https://doi.org/10.21203/rs.3.rs-667372/v1

License: (c) (i) This work is licensed under a Creative Commons Attribution 4.0 International License. Read Full License 
SURVIVAL OF PLANTS DURING SHORT-TERM BOA-OH EXPOSURE: ROS RELATED GENE EXPRESSION AND DETOXIFICATION REACTIONS ARE ACCOMPANIED WITH FAST MEMBRANE LIPID REPAIR IN ROOT TIPS

LAURA LASCHKE ${ }^{1,4}$, VADIM SCHÜTZ ${ }^{1,4}$, OLIVER SCHACKOW ${ }^{2}$, DIETER SICKER ${ }^{2}$, LOTHAR HENNIG $^{2}$, DIANA HOFMANN ${ }^{3}$, PETER DÖRMANN ${ }^{1}$ and MARGOT SCHULZ $^{1 *}$

${ }^{1}$ IMBIO Institute of Molecular Physiology and Biotechnology of Plants, University of Bonn, Karlrobert-Kreiten Str. 13, 53115 Bonn, Germany

${ }^{2}$ Institut für Organische Chemie, Universität Leipzig, Johannisallee 29, 04103 Leipzig, Germany ${ }^{3} I B G$-3: Agrosphäre, Forschungszentrum Jülich GmbH, Jülich, Germany

${ }^{4}$ Authors contributed in experimental work equally

Corresponding author: Margot Schulz, ulp509@uni-bonn.de orcid.org/0000-0001-7373-306X 
Abstract - Exposure of Zea mays seedlings to $0.5 \mu \mathrm{M}$ benzoxazolinone-4/5/6/7-OH allelochemicals elicits root zone specific reactions by formation of dark rings and spots in the zone of lateral roots, high catalase activity at root hairs and no visible defense reaction at the root tip. We studied short term effects on membrane lipids and fatty acids in maize root tips in comparison to those of Abutilon theophrasti after BOA-6-OH incubations. We found a decrease mainly of phosphatidylinositol in Abutilon and phosphatidylcholine in maize after 10-30 min of exposure. In the youngest tissue, $\alpha$-linoleic acid (18:2), decreased considerably in both species but amounts recovered within one hour. Disturbances in membrane phospholipid contents were balanced in both species within 30-60 min. The findings that triacylglycerols (TAGs) were also affected, but levels of maize diacylglycerols (DAG) were almost unchanged, suggested that fatty acids for membrane lipid regeneration are released from TAGs while resulting DAGs are buildings blocks for phospholipid reconstitution, concomitant with BOA6-OH glucosylation. The expression of superoxide dismutase (SOD2) and of ER-bound oleoyl desaturase (FAD2-2) genes were contemporaneously up regulated in contrast to the catalase gene $C A T 1$, while $C A T 3$ was arguably integrated at a later stage of the detoxification process. Major catalase activity seems to be attributed to root colonizing microorganisms. Immunoresponses were not elicited in short-terms, since expression of NPR1, POX12 were rather affected, $P R 4$ after $6 \mathrm{~h}$ with BOA-4/7-OH and $P R 1$ after $24 \mathrm{~h}$ with BOA-5/6-OH. The rapid membrane recovery, reactive oxygen species and allelochemical detoxification may be characteristic for BOA-OH insensitive plants.

Key Words - BOA-OH isomers, ROS, detoxification, FAD2-2, SOD2, Lipids, membrane repair 


\section{INTRODUCTION}

Increase of reactive oxygen species (ROS) is a characteristic feature when plants are exposed to their own allelochemicals or to those from other plants (Gniazdowska and Bogatek 2005; Lara-Nuñez et al. 2006; Huang et al. 2020). $\mathrm{H}_{2} \mathrm{O}_{2}$ and the superoxide anion radical $\left(\mathrm{O}_{2}{ }^{-{ }^{-}}\right)$are key compounds in signaling and cell wall loosening reactions (Baxter et al. 2014; Marino et al. 2012; Liszkay et al. 2004). However, excessive amounts of reactive oxygen species disturb the cellular ROS homeostasis. The imbalance leads to oxidative damage of biomolecules, starting with membrane lipids, which is thought to be one of the major reasons for reduced growth or even death of sensitive plant seedlings with insufficient detoxification capacities. When exposed to allelochemicals, the plasma membrane is the first membrane system contacted. Membrane interactions of hydrophobic allelochemicals or those possessing hydrophobic domains are attributed to membrane leakage, one of the earliest and most harmful injuries caused by toxic allelochemicals (Schulz et al. 2013; Einhellig et al. 1986). For instance, cinnamaldehyde interacts with membrane receptors, whereas allelopathic concentrations of certain monoterpenes disorganize membrane lipids (Lins et al. 2019), some allelochemicals change the membrane potential (Maffei et al. 2001). The allelochemical benzoxazolinone (BOA), for instance, induces oxidative stress in lettuce, mung bean or maize, resulting in enhanced malondialdehyde (MDA) levels (Sanchez-Moreiras and Reigosa 2005; Batish et al. 2006; Schulz et al. 2013). The increase of MDA and conjugated dienes is indicative for lipid/ polyunsaturated fatty acid peroxidation. The loss of membrane functions is a consequence of lipid peroxidation and damaged enzymes anchored therein or otherwise attached (Stark 2005). Although lipid peroxidation caused by allelochemicals was often postulated from increased MDA levels, there is no study addressing the effects on lipids with defined molecular species, and how fast, if at all, repair of membranes is initiated, a prerequisite to reestablish functional membranes. Indeed, prompt membrane regeneration is crucial for the survival of allelochemical attacks and may be characteristic for tolerant plant species.

Benzoxazinones are secondary metabolites found in several grasses and some dicotyledonous species (Sicker et al. 2000; Niemeyer 2009). DIMBOA (2,4-dihydroxy-7-methoxy-2H-1,4benzoxazin-3(4H)-one) and its glucosylated form is the major benzoxazinone in maize. DIMBOA but also DIBOA (2,4-dihydroxy-2H-1,4-benzoxazin-3(4H)-one) which is, for instance, present in rye and old maize leaves, possess biocidal properties, influence growth of plants and microorganisms and can function as antinutrients for sensitive herbivores (Schütz et al. 2019; Hu et al. 2018; Maag et al. 2016; Wouters et al. 2016; Neal et al. 2012; Schulz et al. 2013). 
Benzoxazolin-2(3H)-one is the first degradation product of DIBOA. Less sensitive plants can hydroxylate BOA in position 5 or, preferentially, in position 6 , and immediate glucosylation yields BOA-5/6-O-glucoside as a minor or major detoxification product (Sicker and Schulz 2002). Maize detoxifies BOA mainly via glucoside carbamate, whereas BOA-6- $O$-glucoside is a minor detoxification product occurring only during the early detoxification process. BOA detoxification via glucoside carbamate in maize is accompanied by pronounced shifting of proteins between different cellular compartments (Schulz et al. 2016). In contrast, BOA-6-Oglucoside and methoxylated glucoside carbamate represent major and minor products, respectively, when maize seedlings are incubated with MBOA (Hofmann et al. 2006). BOA-6$O$-glucoside can be detected occasionally in maize roots in low amounts without previous BOA incubation (Schulz et al. 2013). The more toxic intermediate BOA-6-OH does not accumulate in maize but often in seedlings of sensitive dicotyledonous species (Sicker et al. 2004). In contrast, the weed Abutilon theophrasti, which is highly resistant to BOA when cultured in soils rich in organic matter, accumulates low amounts of BOA detoxification products, compared to maize. Instead, other strategies have been evolved to cope with BOA that include root colonizing microorganisms, efficient transporters for BOA efflux, and numerous enzymes for BOA-6-OH polymerization and degradation at the root surface and within the apoplast (Schulz et al. 2017; 2012). A high catalase activity was stated as a response to increased $\mathrm{H}_{2} \mathrm{O}_{2}$ at the root surface when Abutilon seedlings were exposed to BOA-OH isomers. Therefore, membrane damage by lipid peroxidation may occur, at least during the early phase of allelochemical exposure.

In addition to the aforementioned BOA-6- and BOA-5- $O$-glucosides, BOA-4- $O$-glucoside was identified in benzoxazinone- (BXs) containing Acanthus ilicifolius plants (Huo et al. 2005). The isomer BOA-7-OH and its glucoside are not known as natural products. The detoxification behavior of crops, also that of BX containing plants such as maize, is of special interest for estimating the toxicity/ autotoxicity of these compounds because benzoxazinoids are increasingly in the focus for agricultural usage (Macias et al. 2005). For instance, BXcontaining rye mulches are known to suppress certain weeds except for Abutilon theophrasti in sustainable agricultural systems (Tabaglio et al. 2008; Boselli et al. 2021). Moreover, natural compounds with elicitor or priming properties for resistance and immunity of plants are under consideration as agents against diseases.

Maize root membranes contain the phospholipids (PLs) phosphatidylcholine (PC) as the dominant PL, phosphatidylethanolamine (PE), phosphatidylserine (PS), phosphatidylinositol (PI), phosphatidylglycerol (PG), the glycolipids (GLs) monogalactosyldiacylglycerol 
(MGDG), digalactosyldiacylglycerol (DGDG), and low amounts of free fatty acids. Plasma membranes of maize roots are composed predominately of PC and PE, whereas PG, PI and PS are less abundant (Bohn et al. 2001). The glycolipid DGDG is a minor constituent of the plant plasma membrane, and it is located in the cytosolic leaflet (Tjellström et al. 2010; Cacas et al. 2016). PC and PE are also major lipids of mitochondria (Michaud et al. 2017). For Abutilon, no data on membrane lipid composition are available, but in all plants investigated, PLs and GLs are composed of different molecular species that vary in the lengths of the acyl chains and in the number of double bonds. Within the apoplastic and the cytosolic leaflets of the plasma membrane, lipids are asymmetrically distributed, whereby the cytosolic leaflet has a higher content of unsaturated phospholipids. In vegetative tissue, triacylglycerols (TAGs) which are stored in lipid droplets in the cytosol, play a role in stress responses ( $\mathrm{Lu}$ et al. 2020). Diacylglycerols (DAGs) can be synthesized from PA (phosphatidic acid). DAG is an intermediate metabolite in lipid metabolism and a precursor of PC, PE, PG and PS. It can be acetylated to TAG, while hydrolysis of phospholipids or TAG by (phospho)lipases yield again DAG, representing also a signaling molecule. DAGs are in low concentration in the cytoplasmic leaflet of membranes, but are found in higher amounts in the ER, mitochondria and chloroplasts (Vermeer et al. 2017).

In this study, we describe the synthesis of four BOA-OH isomers as compounds causing oxidative stress in maize root tips, and differentiated reactions of the root zones faced with these compounds. We looked for early impacts of BOA-6-OH on root membrane lipids of maize in comparison to the weed Abutilon theophrasti and on membrane recovery by determination of total fatty acids and structural PLs, TAGs and DAGs in maize and Abutilon seedlings. We set focus on the transient disturbance of lipid and fatty acid contents in the root tips when exposed to prevalent BOA-6-OH and the subsequent restoration of the lipid pools. Also, the influence on superoxide dismutase $(S O D)$ and catalase $(C A T)$ gene expressions for ROS detoxification and on desaturase $F A D 2$ genes for unsaturated fatty acid regeneration in the youngest and most vulnerable root tissue was studied. We searched for a coordination of membrane repair, ROS elimination, BOA-OH detoxification and presumable links to pathogenesis and resistance in maize root tips.

\section{METHODS AND MATERIALS}

Syntheses of Hydroxylated BOA Species 
Except for BOA-6-OH, hydroxylated benzoxazolinones are commercially not available. Therefore, the isomers of hydroxylated benzoxazolinones, including BOA-6-OH, were synthesized to compare their detoxification in maize seedlings and to study gene expression. However, the laborious syntheses and yields of the different isomers did not allow to perform all experiments with all isomers.

2-Nitroresorcinol (1) was prepared by nitration of resorcinol with conc. $\mathrm{H}_{2} \mathrm{SO}_{4}$ and $67 \% \mathrm{HNO}_{3}$. 1 was isolated by steam distillation as orange crystals ( $24 \%$ yield, $11 \mathrm{~g}$ ). The melting points (mp) of $85^{\circ} \mathrm{C}$ was in accordance with Schaffrath (1970). NMR spectra confirmed the structure: ${ }^{1} \mathrm{H}-\mathrm{NMR}\left(\mathrm{CDCl}_{3}, 300 \mathrm{MHz}\right) \delta 10.65(2 \mathrm{H}, \mathrm{s}, \mathrm{O}-\mathrm{H}), 7.44(1 \mathrm{H}, \mathrm{t}, J=8.4 \mathrm{~Hz}, \mathrm{H}-5), 6.61(2 \mathrm{H}, \mathrm{d}$, $J=8.4 \mathrm{~Hz}, \mathrm{H}-4, \mathrm{H}-6) .{ }^{13} \mathrm{C}-\mathrm{NMR}\left(\mathrm{CDCl}_{3}, 75 \mathrm{MHz}\right) \delta 156.5$ (C, C-1, C-3). 138.9 (CH, C-5), 123.9 (C, C-2), 109.6 (CH, C-4, C-6).

2-Nitrohydroquinone (2) was prepared by the classical Elbs oxidation of 2-nitrophenol with $\mathrm{K}_{2} \mathrm{~S}_{2} \mathrm{O}_{8}$ in diluted $\mathrm{NaOH}$ solution (Elbs 1893). 2 was obtained as dark red crystals in $9 \%$ yield and $3 \mathrm{~g}$ amount. The purification was done by removal of unreacted 2-nitrophenol by steam distillation followed by extraction of $\mathbf{2}$ from the residue with MTBE (methyl $t$-butyl ether) and a final crystallization of the MTBE extract from water. The mp of $131-132{ }^{\circ} \mathrm{C}$ is in accordance with the data of Elbs (1893). ${ }^{1} \mathrm{H}-\mathrm{NMR}$ (DMSO-d $\left.6,300 \mathrm{MHz}\right) \delta 10.14$ (1 H, brs, O-H), 9.60 (1 H, brs, O-H), $7.22(1 \mathrm{H}, \mathrm{d}, J=2.9 \mathrm{~Hz}, \mathrm{H}-3), 7.02(1 \mathrm{H}, \mathrm{dd}, J=9.0,2.9 \mathrm{~Hz}, \mathrm{H}-5), 6.96$ (1 H, d, $J$ $=9.0 \mathrm{~Hz}, \mathrm{H}-6) .{ }^{13} \mathrm{C}-\mathrm{NMR}\left(\mathrm{DMSO}-\mathrm{d}_{6}, 75 \mathrm{MHz}\right) \delta 149.7$ (C, C-4), 145.1 (C, C-1), 135.8 (C, C2), $124.3(\mathrm{CH}, \mathrm{C}-5), 120.1$ (CH, C-6), 109.5 (CH, C-3).

4-Nitroresorcinol (3) was prepared from resorcinol according to the recent nitration method of Samajdar et al. (2000) with silica gel-supported $\mathrm{Bi}\left(\mathrm{NO}_{3}\right)_{3}$ x $5 \mathrm{H}_{2} \mathrm{O}$ with some variations (silica gel instead of montmorillonite, no microwave irradiation, $\mathrm{CH}_{2} \mathrm{Cl}_{2}$ as solvent during the reaction with the supported reagent). 3 was isolated by extraction with $\mathrm{CHCl}_{3}$ and purified by flash chromatography over silica gel (eluent $n$-hexane/ethyl acetate 2:1 v/v) as yellow crystals in $26 \%$ yield and $2 \mathrm{~g}$ amount. The $\mathrm{mp}$ of $120^{\circ} \mathrm{C}$ is in accordance with Kauffmann and Kugel (1911). ${ }^{1} \mathrm{H}-\mathrm{NMR}$ (DMSO-d $\left.6,300 \mathrm{MHz}\right) \delta 10.95$ (1 H, brs, O-H), 10.80 (1 H, brs, O-H), 7.88 (1 H, d, J $=9.1 \mathrm{~Hz}, \mathrm{H}-5), 6.42(1 \mathrm{H}, \mathrm{d}, J=2.4 \mathrm{~Hz}, \mathrm{H}-6), 6.39(1 \mathrm{H}, \mathrm{dd}, J=9.1,2.4 \mathrm{~Hz}, \mathrm{H}-2) .{ }^{13} \mathrm{C}-\mathrm{NMR}$ (DMSO-d 6,75 MHz) $\delta 164.9$ (C, C-1), 156.0 (C, C-3), 128.1 (C, C-4), 127.8 (CH, C-5), 108.8 (CH, C-6), 103.6 (CH, C-2).

3-Nitrocatechol (4) was prepared by nitration of an ethereal solution of catechol with 100\% fuming nitric acid according to Rosenblatt et al. (1953). 3 was separated from the accompanying 4 -nitrocatechol by steam distillation as dark yellow crystals in $15 \%$ yield and $4 \mathrm{~g}$ amount. The mp of $87{ }^{\circ} \mathrm{C}$ was in accordance with the literature (Samajdar et al. 2000). ${ }^{1} \mathrm{H}-\mathrm{NMR}\left(\mathrm{CDCl}_{3}, 300\right.$ 
MHz) $\delta 10.62$ (1 H, brs, O-H), 7.65 (1 H, dd, $J=8.7,1.5 \mathrm{~Hz}, \mathrm{H}-4), 7.24$ (1 H, dd, $J=8.4,1.2$ $\mathrm{Hz}, \mathrm{H}-6), 6.91(1 \mathrm{H}, \mathrm{dd}, J=8.7,8.4 \mathrm{~Hz}, \mathrm{H}-5), 5.82(1 \mathrm{H}, \mathrm{brs}, \mathrm{O}-\mathrm{H}) .{ }^{13} \mathrm{C}-\mathrm{NMR}\left(\mathrm{CDCl}_{3}, 75 \mathrm{MHz}\right)$ $\delta 146.5$ (C, C-1), 142.8 (C, C-2), 133.8 (C, C-3), 121.7 (CH, C-5), 119.8 (CH, C-6), 115.8 (CH, C-4).

\section{General Method for the Synthesis of the Hydroxy-Substituted BOAs 5-8.}

In a glass hydrogenation flask, $1.54 \mathrm{~g}(9.9 \mathrm{mmol})$ of the corresponding nitro compound (compounds 1-4) were dissolved in $150 \mathrm{ml}$ of dry THF followed by $0.5 \mathrm{~g} \mathrm{Pd} / \mathrm{C}$ catalyst. The mixture was stirred under hydrogen from a balloon at standard pressure for $6 \mathrm{~h}$. The $\mathrm{H}_{2}$ balloon was then removed, the flask was cooled in an ice water bath and $2.3 \mathrm{~g}(22 \mathrm{~mol} ; 3.0 \mathrm{ml})$ triethylamine was added at once followed by dropwise addition of $0.8 \mathrm{~g}(2.6 \mathrm{mmol})$ triphosgene dissolved in $50 \mathrm{ml}$ dry THF over a dropping funnel within $3 \mathrm{~min}$. The mixture was stirred for $30 \mathrm{~min}$. Then, the catalyst and the triethylamine hydrochloride were filtered. The solvent was removed from the filtrate in vacuo. The remaining residue was purified by column chromatography using $\mathrm{CH}_{2} \mathrm{Cl}_{2}$ /methanol 10:1 as the eluent. An exception is compound 7. All melting points given here were in accordance with those reported by Zinner and Wigert (1960), who used a different urea-based synthesis. The structures were further confirmed by ${ }^{1} \mathrm{H}-$ and ${ }^{13}$ C-NMR, IR and MS. NMR analyses were done with DRX-400 and Fourier 300 instruments (Bruker). The IR-spectra were obtained with a Fourier Transform Infrared Spectrometer FT/IR4100 (JASCO). The EI-MS data were acquired on a MAT 8230 spectrometer (Thermo Fisher, formerly Finnigan MAT). Melting points were determined with a Boëtius micro hot stage.

4-Hydroxybenzoxazolin-2(3H)-one 5: Yield: $998 \mathrm{mg}$ (66 \%) off-white crystals, mp. 288-289 ${ }^{\circ} \mathrm{C}$ (Zinner and Wigert 1960: 281-283 ${ }^{\circ} \mathrm{C}$ ). ${ }^{1} \mathrm{H}-\mathrm{NMR}$ (DMSO-d $\left.6,300 \mathrm{MHz}\right) \delta 10.69(2 \mathrm{H}$, brs, O-H, N-H), $6.86(1 \mathrm{H}, \mathrm{t}, J=8.2 \mathrm{~Hz}, \mathrm{H}-6), 6.71(1 \mathrm{H}, \mathrm{d}, J=8.2 \mathrm{~Hz}, \mathrm{H}-7), 6.63(1 \mathrm{H}, \mathrm{d}, J=8.2 \mathrm{~Hz}$, H-5). ${ }^{13}$ C-NMR (DMSO-d 6,75 MHz) $\delta 154.5$ (C, C-2), 144.7 (C, C-7a), 142.0 (C, C-4), 122.0 (CH, C-6), 118.2 (C, C-3a), 110.9 (CH, C-5), 100.9 (CH, C-7). IR (KBr): $\widetilde{v}\left[\mathrm{~cm}^{-1}\right]=3449$, 3287, 1738, 1476, 1024. EI-MS m/z (\%): 151(M+, 100), 79 (29), 67 (30), 57 (60), 43 (39).

5-Hydroxybenzoxazolin-2(3H)-one 6: Yield: $651 \mathrm{mg}$ (43\%) beige crystals, mp. $212-213^{\circ} \mathrm{C}$ (Zinner and Wigert 1960: 209-210 $\left.{ }^{\circ} \mathrm{C}\right) .{ }^{1} \mathrm{H}-\mathrm{NMR}\left(\mathrm{DMSO}_{6}, 300 \mathrm{MHz}\right) \delta 11.33(1 \mathrm{H}, \mathrm{brs}, \mathrm{N}-$ H), 9.36 (1 H, brs, O-H), 7.02 (1 H, d, $J=8.6 \mathrm{~Hz}, \mathrm{H}-7), 6.47$ (1H, d, $J=2.4 \mathrm{~Hz}, \mathrm{H}-4), 6.41$ (1 $\mathrm{H}, \mathrm{dd}, J=8.6,2.4 \mathrm{~Hz}, \mathrm{H}-6) .{ }^{13} \mathrm{C}-\mathrm{NMR}$ (DMSO-d $\left.6,75 \mathrm{MHz}\right) \delta 155.1$ (C, C-2), 154.1 (C, C-5), 136.3 (C, C-7a), 131.0 (C, C-3a), 109.9 (CH, C-7), 108.0 (CH, C-6), 97.4 (CH, C-4).IR (KBr): $\tilde{v}\left[\mathrm{~cm}^{-1}\right]=3541,3464,3285,1731,1482,1172$. EI-MS m/z (\%): 151(M+, 100), 95 (95), 68 (36), 67 (32), 41 (29). 
6-Hydroxybenzoxazolin-2(3H)-one 7: A black solid remained after removal of the solvent in vасио. It was refluxed for $10 \mathrm{~min}$ along with $0.5 \mathrm{~g}$ activated charcoal powder and $200 \mathrm{ml}$ of distilled water. It was then filtered and cooled to yield $250 \mathrm{mg}(17 \%)$ of 7 as colorless crystals, mp $299{ }^{\circ} \mathrm{C}$ (Zinner and Wigert 1960: $288-292^{\circ} \mathrm{C}$ ). Due to the high mp, the solubility of 7 is poor and column chromatography was not advisable. ${ }^{1} \mathrm{H}-\mathrm{NMR}$ (DMSO-d $\left.6,300 \mathrm{MHz}\right) \delta$ 11.24 (1 H, brs, N-H), 9.36 (1 H, brs, O-H), 6.86 (1 H, d, $J=8.5 \mathrm{~Hz}, \mathrm{H}-4), 6.69(1 \mathrm{H}, \mathrm{d}, J=2.2$ $\mathrm{Hz}, \mathrm{H}-7), 6.55$ (1 H, dd, $J=8.5,2.2 \mathrm{~Hz}, \mathrm{H}-5) .{ }^{13} \mathrm{C}-\mathrm{NMR}$ (DMSO-d 6 , $75 \mathrm{MHz}$ ) $\delta 154.8$ (C, C-2), 153.1 (C, C-6), 144.1 (C, C-7a), 122.3 (C, C-3a), 110.1 (CH, C-5), 109.9 (CH, C-4), 98.0 (CH, C-7). IR (KBr): $\tilde{v}\left[\mathrm{~cm}^{-1}\right]=3458,3214,1734,1499,1106$. EI-MS m/z (\%): 151(M+, 100), 95 (87), 67 (39), 52 (46), 41 (31).

7-Hydroxybenzoxazolin-2(3H)-one 8: Yield: $420 \mathrm{mg}(29 \%)$ beige crystals, mp 236-238 ${ }^{\circ} \mathrm{C}$ (Zinner and Wigert, 1960: $232{ }^{\circ} \mathrm{C}$ ). ${ }^{1} \mathrm{H}-\mathrm{NMR}$ (DMSO-d $\left.6,300 \mathrm{MHz}\right) \delta 10.50(2 \mathrm{H}$, brs, N-H, OH), $6.90(1 \mathrm{H}, \mathrm{dd}, J=8.4,7.8 \mathrm{~Hz}, \mathrm{H}-5), 6.56(1 \mathrm{H}, \mathrm{dd}, J=8.4,1.1 \mathrm{~Hz}, \mathrm{H}-4), 6.51(1 \mathrm{H}, \mathrm{dd}, J=$ 7.8, $1.1 \mathrm{~Hz}, \mathrm{H}-6) .{ }^{13} \mathrm{C}-\mathrm{NMR}$ (DMSO-d $\left.6,75 \mathrm{MHz}\right) \delta 154.5$ (C, C-2), 140.9 (C, C-7), 131.8 (C, C-3a), 131.1 (C, C-7a), 124.2 (CH, C-5), 110.3 (CH, C-4), 110.9 (CH, C-6).

IR (KBr): $\tilde{v}\left[\mathrm{~cm}^{-1}\right]=3360,3261,1768,1383,1150$. EI-MS m/z (\%): 151(M+, 100), $96(47)$, 68 (36), 67 (40), 52 (33).

\section{Plant material}

Caryopses of Zea mays cultivar Cassila (KWS, Germany) were hydroponically grown for 7 days as described in Schulz et al. (2016). For the analysis of detoxification products, the seedlings were incubated with the BOA-isomers for $24 \mathrm{~h}$ ( 3 seedlings/ $20 \mathrm{ml}$ of $0.5 \mathrm{mM}$ of one of the isomers in tap water). For analysis of BOA-6-O-glc accumulation during short term exposure, seedlings were incubated $0,10,20,30,40,50$ and 60 min with $0.5 \mu \mathrm{M}$ BOA-6-OH. Analysis and determination of the detoxification products was performed by HPLC using the system and the method described below. For preparation of $500 \mathrm{ml}$ incubation solution the isomers were pre-solved in $1 \mathrm{ml}$ methanol and sonicated for $5 \mathrm{~min}$ before adding tap water. Root extracts were performed as described in Schulz and Wieland (1998). Peroxidase activity at living root surfaces was detected by bathing the roots (1 seedling / $15 \mathrm{ml}$ Falcon tube) in 10 $\mathrm{ml} 0.1 \mathrm{mM}$ acetate buffer $\mathrm{pH} 5.0$ supplemented with $1.6 \mathrm{ml} 2 \mathrm{mM}$ ABTS (Roche Diagnostics, Germany) and $0.6 \mathrm{ml} 15 \mathrm{mM} \mathrm{H} \mathrm{H}_{2} \mathrm{O}_{2}$ (Sigma-Merck, Germany). Sites with peroxidase activity immediately turned dark or black-green. Catalase activity elicited by BOA-6,5,4-OH was concluded from bubble formation according to Schellhorn and Stones (1992) and Wheelis (2008), presenting a non-destructive method. 


\section{Culture of root colonizing microorganisms}

For collection of root surface colonizing microorganisms, maize was grown from seeds without surface sterilization and incubated as described above. Microorganisms from the root surfaces were collected by washing with water and pelleted by centrifugation at $4000 \mathrm{~g}$ for $5 \mathrm{~min}$ at $20^{\circ} \mathrm{C}$. After resuspension, they were grown in LB medium for three days, then plated on Czapek agar and cultured for 3 days before applying $300 \mu \mathrm{l}$ of aqueous $0.5 \mathrm{mM}$ of the BOA-4/5/6-OH, pre-dissolved in $\mathrm{MeOH}$. The control was treated with the amount of $\mathrm{MeOH}$ applied with the aqueous BOA-OH solutions.

\section{Benzoxazinoids in Root Hairs and their Wash Solutions}

For the harvest of root hairs, maize was germinated on wet filter paper placed in Petri dishes. Approximately $1 \mathrm{mg}$ root hairs from six 7-day-old maize seedlings were cut and immediately collected in a cap with $500 \mu 170 \%$ ice cold methanol $(n=12)$. From another six seedlings, root hair zones were washed with $500 \mu \mathrm{l}$ water and the wash solutions including the mucilage drops (see below) collected in pure methanol, yielding a 50\% solution. Four wash solutions collected over a period of $4 \mathrm{~h}$ were combined for one sample. Root hair extracts and wash solutions were analyzed by HPLC/ DAD (Shimadzu, Germany), equipped with a RP-18 column (MachereyNagel, Düren, EC 250/4.6 Nucleodur 100-5 C18). Linear gradients were run with $0.01 \%$ formic $\mathrm{acid} / \mathrm{H}_{2} \mathrm{O}$ and methanol within $35 \mathrm{~min}$. For confirmation of the compounds identity, root hair extracts were subsequently analyzed by Ultra Performance Liquid Chromatography (UPLC)electrospray (ESI)-mass spectrometry (Waters, Eschborn) as described in Schulz et al. (2016). Mucilage drops from the root tips of 6 seedlings were collected on ice with a syringe and analyzed by HPLC. Since only traces of the BXs were found, further wash solutions contained washes of root hair zone including the mucilage drops $(n=7)$.

\section{Lipid Analyses}

For total fatty acids methyl ester (FAME) determinations, 35 root tips $(0-2 \mathrm{~cm}$, further named $\mathrm{ZmRTa}) / \mathrm{sample}$ and 10 older root parts $(2-4 \mathrm{~cm}$, further named ZmRTb)/sample from maize and 13 root tips (AbRTa)/ sample and 7 older root parts (AbRTb)/sample from Abutilon theophrasti were harvested without incubation and after 10, 20, 30, 40, 50 and $60 \mathrm{~min}$ incubations in $0.5 \mathrm{mM}$ BOA-6-OH. For these experiments, BOA-6-OH was purchased from Merck-Sigma. The harvested root material from each incubation time was immediately treated 
with boiling water for $20 \mathrm{~min}$, followed by $3 \mathrm{x}$ repeated chloroform/methanol (1:2), (1 $\mathrm{ml} / \mathrm{sample}$ ) extractions. The resulting three portions of crude lipid extracts were combined and purified by addition of $0.75 \mathrm{ml} 0.3 \mathrm{M}$ ammonium acetate. After centrifugation at $2000 \mathrm{~g}$ for 5 min, the lipid phase was dried under $\mathrm{N}_{2}$. When not directly analyzed, the extracts were stored at $-20{ }^{\circ} \mathrm{C}$ until analysis. The extracted root material was dried overnight at $104{ }^{\circ} \mathrm{C}$ for dry weight determination. The described extraction method followed the procedure described by Siebers et al. (2018). The conversion of fatty acids into fatty acids methyl esters (FAMEs) was done according to Browse et al. (1986). For quantification pentadecanoic acid, (15:0) was added as internal standard to the samples. FAMEs were analyzed using an Agilent 7890 gas chromatograph with Supelco SP-2380 capillary column and a flame ionization detector (7890 Gas chromatograph (GC) with flame ionization detector (FID) Agilent, Böblingen (D) as described in Siebers et al. (2018). The oven temperature was $100{ }^{\circ} \mathrm{C}$ initially, increased to 160 ${ }^{\circ} \mathrm{C}$ at $25^{\circ} \mathrm{C} \mathrm{min}^{-1}$, and finally ramped to $220{ }^{\circ} \mathrm{C}$ at $10{ }^{\circ} \mathrm{C} \mathrm{min}^{-1}$. Fatty acid peaks were identified using FAME standards (Sigma-Aldrich, Supelco® 37 Component FAME Mix).

For the measurement of phospholipids, glycolipids, phospholipid fatty acid (PLFA) analyses and determinations of TAGs and DAGs, 4 maize root parts/sample (see above) or 7 root parts/sample of Abutilon were extracted as described. Lipid extraction and analysis were according to Bravo et al. (2017). Lipids were fractionated according to their polarity by solid phase extraction (Gasulla et al. 2013; Siebers et al. 2018; Schütz et al. 2021). The fractionated phospholipids were methanolized and converted into their methyl esters prior to measurement by GC (Browse et al. 1986). The contents and molecular species composition of phospholipids/glycolipids, TAGs and DAGs were determined by direct infusion mass spectrometry on an Agilent Accurate Mass quadrupole time-of-flight (Q-TOF) mass spectrometer. Quantification of lipid molecular species was performed by MS/MS analysis.

\section{Gene Expression Studies}

\section{Choice of Genes}

The selection of genes for comparative expression studies was restricted to SOD2, CAT 1, CAT 3, FAD2-1, FAD2-2, PR1, PR4 and POX 12 because of the limited amounts of BOA-4, 5- and 7-OH available for the experiments. This set of genes was selected to give first clues on the oxidative stress elicitation by $\mathrm{BOA}-\mathrm{OH}$ isomers, lipid repair and possible relations to plant immune responses in the youngest root tissues, thought as a preliminary base for future in depth investigations. Superoxide dismutase 2 (SOD2) involved in superoxide radical transfer to $\mathrm{H}_{2} \mathrm{O}_{2}$ was included as an indicator for ROS stress (Gond et al. 2015). Mitochondrial catalase (CAT3) 
gene is responsive to $\mathrm{H}_{2} \mathrm{O}_{2}$, reactive oxygen species and xenobiotics. Transcripts were detected in the root, epicotyl, and leaves (Redinbaugh et al. 1990). CAT1 was described to be expressed in roots, shoot, and scutellum of young seedlings (Scandalios et al. 1983). While the CAT1 expression is responsive to oxidative stress, the protein is localized to the cytosol (Mylona et al. 2007). CAT 2 expression was described to be light responsive and was therefore not included in the studies (Guan et al. 1996). Expression of members of the complex gene families with functions in the glutathione-ascorbate (GSH-ASC) cycle could not be addressed in this study. The gene expression of two ER-bound oleoyl desaturases (FAD2-1 and FAD2-2) was studied in context with lipid restoration processes after BOA-6-OH exposure. The enzymes synthesize linoleic acid (18:2) mostly in non-photosynthetic tissue (Dar et al. 2017). The seed and bud specific desaturase FAD2-1 was considered not to be responsive, but effects of allelochemicals on FAD2-1 expression are not known. FAD2-2 was described as lowly expressed during the entire life cycle of the plant. To study whether the BOA-OHs induce the expression of genes related to pathogenesis and resistance, induction of POX 12, PRI, PR4 and NPRI expression was studied (Sajad et al. 2018; Backer et al. 2019; Hemetsberger et al. 2012). Primers are given in Tab. S 1 .

RNA Isolation, cDNA Synthesis and $q R T-P C R$

7-day-old maize seedlings were incubated with $0.5 \mathrm{mM}$ of the BOA-OH isomers for $30 \mathrm{~min}, 1$ $\mathrm{h}$ and $6 \mathrm{~h}$, for SOD2 expression, BOA-6/5-OH samples in addition for $24 \mathrm{~h}$, for FAD2-2 expression all isomers also for $24 \mathrm{~h} .100 \mathrm{mg}$ Root tips were cut $(3 \mathrm{~cm})$ and immediately frozen in liquid nitrogen until RNA was extracted. The material was homogenized with the Precellys® 24 / 24-Dual (PEQLAB Biotechnologie, Erlangen) and RNA was isolated with the NucleoSpin RNA Plant Kit (Macherey and Nagel, Düren) according the instructions of the manufacturer. For cDNA preparation the Thermo Scientific RevertAid First Strand cDNA Synthesis Kit was used. RT-PCR was performed with a 7300 real time PCR system (Applied Biosystems, Darmstadt). The reaction mixture $(20 \mu \mathrm{l})$ consisted of $4 \mu \mathrm{l} \mathrm{H}_{2} \mathrm{O}, 5 \mu \mathrm{l}$ cDNA, $1 \mu \mathrm{l}$ primer pair (working solution $10 \mathrm{pmol} / \mu \mathrm{l}$ ) and $10 \mu \mathrm{l}$ 5xEvaGreen (ROX)qPCR-Mix II (Bio-Budget Technologies, Krefeld, Germany). Gene expression was determined relative to the control plants and to ZmActin as reference gene. For evaluation of RT-qPCR results, the $\Delta \Delta$ ct method was applied. 


\section{Statistics}

Bars, presented with SD, were established with data obtained from three biological replicates unless otherwise noted. Statistical analysis of all the data was done with the t-test. Data in the figures are presented as the mean \pm standard deviation. Significant differences between samples and the controls are indicated: $* \mathrm{p}<0.05 ; * * \mathrm{p}<0.005 ; * * * \mathrm{p}<0.0005$.

\section{RESULTS}

\section{Synthesis of Hydroxybenzoxazolin-2(3H)-ones and their Precursors}

All four hydroxy benzoxazolin-2(3H)-ones (5-8) were prepared from the corresponding nitro precursors 1-4 (Fig. 1) which, in turn, have been synthesized from resorcinol, hydroquinone or catechol, respectively.

By hydrogenation of the nitro compounds in THF over Pd/C, the related amino compounds were obtained which have not yet been isolated in substance, due to their sensitivity towards oxygen. Instead, they have been directly subjected to CO insertion using triphosgene as the carbonyl source in the presence of triethylamine (Fig. 2). This method has first been described for the synthesis of the 6-methoxy analogue MBOA (Sicker 1989).

The solubility of the compounds in methanol decreased in the following order: BOA-4$\mathrm{OH}>\mathrm{BOA}-5-\mathrm{OH}>\mathrm{BOA}-6-\mathrm{OH}>\mathrm{BOA}-7-\mathrm{OH}$. The isomeric BOA-OHs were used for incubations of maize seedlings to reveal possible differences in the reaction of the root.

\section{Determination of Benzoxazinoid (BX) Contents in Cut Root Hair Extracts and Wash Solutions}

To estimate benzoxazinoid concentrations which are released, but are not harmful for roots of the maize cultivar Cassila, the amounts of the major BX compounds, present in root hairs and wash solutions, were determined. These measurements verified that exudates did not contain detectable amounts of BOA-6-OH or its glucoside.

Emerging lateral roots destroy epidermal tissue, which leads only to a transient release of benzoxazinoids (Park et al. 2004). The major release of the compounds is therefore thought to take place by other mechanisms. Analyses of extracts from cut root hairs and of root hair zone wash solutions indicate that root hairs contain BXs and release the major portion of DIMBOA- 
glc/DIMBOA, either by active exudation or passively during root hair necrosis (Fig. 3). Indeed, a passive exudation of BXs during root hair necrosis is more likely, since specific inhibitors of membrane transporters did not suppress the release of BXs (Niculaes et al. 2018). Some detected MBOA indicated degradation. Amounts varied considerably (1 mg cut root hairs: 6.71.7 nmol DIMBOA-glc, 3.3 - 1.0 nmol DIMBOA and 3.0 - $0.2 \mathrm{nmol}$ MBOA; root hair washing solution including mucilage drops/seedling: 1.1-1.2 nmol DIMBOA-glc, 1.8-4.2 nmol DIMBOA, 0.2-0.35 nmol MBOA). Neal et al. (2012) determined DIMBOA contents in exudates of $1 \mathrm{~g}$ fresh roots up to $31 \mu \mathrm{g}$ after a $7 \mathrm{~h}$ collection. Although the data cannot be directly compared because of the different experimental design, the amounts released may be in a similar range. The identity of the compounds was ascertained by LC-MS/MS (DIMBOAGlc: $372(\mathrm{M}-\mathrm{H})^{-}, 396(\mathrm{M}+\mathrm{Na})^{+} 396$ (6), 379 (4), 364 (3), 350 (4), 332 (3), 278 (4), 231 (48), 203 (25), 185 (100), $137(8), 110$ (33); DIMBOA: $212(\mathrm{M}+\mathrm{H})^{+}, 234(\mathrm{M}+\mathrm{Na})^{+}, 250(\mathrm{M}+\mathrm{K})^{+} 212$ (5), 194 (8), 180 (9), 177 (34), 162 (32), 151 (36), 139 (18), 125 (8), 111 (100); MBOA: 164 $(\mathrm{M}-\mathrm{H})^{-}, 166(\mathrm{M}+\mathrm{H})^{+}, 188(\mathrm{M}+\mathrm{Na})^{+} 166(100), 151(45), 138$ (8), 123 (10), 122 (25), 110 (63), 107 (17), 95 (5). BOA-6-OH or its glucoside was not detected in any of the samples. With this background, the chosen BOA-OH concentration of $500 \mu \mathrm{M}$ for the subsequent experiments was thought to be high enough to elicit stress reactions in the root tip.

\section{Response of root zones exposed to BOA-OHs}

During incubation, the older parts of the maize roots developed dark brown spots and rings at areas where lateral roots emerged, whereas the tips stayed white. The dark rings and spots indicate polymerization of the hydroxylated BOA-OHs most likely by peroxidases, as concluded from root surface peroxidase assays with ABTS (Fig. 4). Lateral root emergence is known to be accompanied by high peroxidase III abundance and $\mathrm{H}_{2} \mathrm{O}_{2}$ /ROS production (Orman-Ligeza et al. 2016). Consequently, polymer deposition is especially high at the sites of lateral root emergence. The root hair zone and the root tip (root cap, meristem and the beginning of the elongation zone) showed a different reaction compared to the older root parts with emerging and developed lateral roots. The root hair zone and the tip did not develop brownish spots or rings when incubated with the BOA-OH isomers. The root hairs reacted with bubble formation shortly after start of the incubation, which is indicative for $\mathrm{H}_{2} \mathrm{O}_{2}$ generation and its destruction by catalase, releasing $\mathrm{O}_{2}$. Destruction of $\mathrm{H}_{2} \mathrm{O}_{2}$ may prevent peroxidase dependent polymer formation (Schellhorn and Stones 1992), (Fig. 5). Bubble formation at root hairs subsided during the course of incubation. Only few bubbles developed at the root tips after $6 \mathrm{~h}$ of incubation. Root surface colonizing microorganisms seem to contribute to ROS 
detoxification. Microorganisms freshly collected from the maize root reacted as well with bubble formation when treated with BOA-OH isomers (Fig. 5). As demonstrated in a former study, also Abutilon developed bubble formation as a response of BOA-OH treatment which was however not restricted to root hairs, but covered the entire root during the early phase of incubation. Polymerization of BOA-OHs on Abutilon roots was supported by microorganisms (Schulz et al. 2017).

The surfaces of maize root tips and the tips of lateral roots showed low peroxidase activity with the ABTS assay at root tips of control plants and those after BOA-OH exposure (Fig. 5). BOA$\mathrm{OH}$ incubated root tips and root hairs did not develop polymer coats. Thus, the root tips developed less visible reactions upon BOA-OH exposure than the root hairs or older root zones. Since root tips are known to be most sensitive to allelochemicals, membrane damage was assumed to occur. Therefore, we investigated effects on membrane lipids and fatty acids in maize root tips in comparison to Abutilon root tips after BOA-6-OH incubations.

\section{Effects of BOA-6-OH on Lipids}

\section{Total Unsaturated (UFA) and Saturated Fatty Acids}

In higher plants, the most abundant fatty acids are oleic acid (18:1), linoleic acid (18:2), and $\alpha$ linolenic acid (18:3). Under stress, the accumulation of free fatty acids in plant membranes is increased. Since unsaturated fatty acids (UFAs) are particularly susceptible to oxidation, we started with the determination of total UFAs in comparison to saturated fatty acid contents in the youngest $(\mathrm{RTa})$ and older root tip parts $(\mathrm{RTb})$.

In the maize RTa and RTb samples, linoleic acid (18:2) is the main UFA, followed by $\alpha$ linolenic acid (18:3), which is similar in amount as found for oleic acid. The analyses of the ZmRTa samples disclosed a significantly decreased free linoleic acid content 20 and $30 \mathrm{~min}$ after BOA-6-OH exposure. Regeneration of the t0 level was already accomplished after $40 \mathrm{~min}$ and at $60 \mathrm{~min}$, no further decrease was observed. Except for a significant increase of oleic acid after $40 \mathrm{~min}$, there was no other effect on $\alpha$-linolenic acid and oleic acid contents during the entire course of incubation. In the ZmRTb samples, linoleic acid increased in tendency during BOA-6-OH exposure, but the effect was not significant. In contrast, $\alpha$-linolenic acid increased significantly after $10 \mathrm{~min}$ and stayed constantly higher during the next $40 \mathrm{~min}$, then dropped to the t0 value. During this period, also the amounts of oleic acid was higher. In both series, significant changes in the contents of saturated fatty acids were not detected (Fig 6). 
In Abutilon $\mathrm{RTa} / \mathrm{RTb}$ samples, linoleic acid and $\alpha$-linolenic acid are the major total UFAs. With AbRTa, a significant decrease (approx. 50\%) of both UFAs after 20 and 30 min was found. Their regeneration to t0 levels was reached after $40 \mathrm{~min}$. In contrast to maize, a significant decrease of UFAs was also observed in the AbRTb samples after 20 and $30 \mathrm{~min}$. The subsequent regeneration was as found for AbRTa (Fig. 7). Major saturated fatty acids in Abutilon are palmitic acid (16:0) and stearic acid (18:0). Whereas stearic acid contents were not significantly affected, the ones of palmitic acid were reduced after 20 and 30 min of incubation with a regeneration to the t0 level after $40 \mathrm{~min}$. The reduction was found in both sample series (AbRTa and $\mathrm{AbRTb}$ ), with a stronger one in the youngest tissue, where a loss of about $50 \%$ of palmitic acid was measured. Thus, root tips of A. theophrasti are more affected than those of maize. Nevertheless, both species exhibit a remarkable fast regeneration of the fatty acid contents found at t0. The decrease of UFAs, and in case of Abutilon also the decrease of saturated fatty acids, is balanced already after $40 \mathrm{~min}$.

For clues of structural phospholipid and glycolipid damage, their contents in the $\mathrm{RTa} / \mathrm{RTb}$ series of both plants were determined and compared with the levels found in untreated roots set as t0 control (Fig. 8). In extra-chloroplast membranes, phosphatidylcholine (PC) and phosphatidylethanolamine (PE) are the dominant constituents.

In the maize ZmRTa samples, only one of the major phospholipids, PC with the molecular species 34:2 and 34:4 (molecular species are shown in Fig. S1), was reduced during the first 30 min of BOA-6-OH incubation, then regenerated finally reaching t0 levels. PI and PG fluctuations followed the same trend, whereas DGDG, different to MGDG, had the trend to increase. However, these alterations were not significant. In the ZmRTb samples, only PC with the same molecular species as mentioned before, was affected, but in contrast to ZmRTa, the t0 level was not yet reconstituted after $1 \mathrm{~h}$.

In the Abutilon samples, galactoglycerolipid levels were not changed (Fig. 8). The most pronounced difference to maize was the significant decrease of phosphatidylinositol (PI) with the molecular species 34:3 and 34:2 in both sample series (AbRTa/b) during the first 20 min, followed by fast regeneration. In AbRTa, PC levels increased significantly after $30 \mathrm{~min}$. Total PE content had a trend to increase after 20 and $30 \mathrm{~min}$, but defined molecular species reacted differently (Fig. S1). For instance, PE 34:2 decreased during the first 20 min after start of the incubation, while in ABRTb samples PE 34:2 levels were almost not affected, although total PE decreased (Fig. 8; S1). Total PC levels fluctuated without significance. However, regarding the molecular species, we found significant fluctuations with PC 34:3, 34:2 and 36:5. Thus, responsiveness of phospholipids to BOA-6-OH was selective, depended on molecular species 
and varied between the two plant species, with PC 34:2/34:4 as the significantly affected ones in maize and PI (34:3/34:2) in both Abutilon series. Finally, triacylglycerols (TAGs) and diacylglycerols (DAGs) contents were determined (Fig. 9). In the maize RTa samples, TAGs did not increase significantly above the t0 levels during the course of BOA-6-OH exposure. Instead, a significant decrease, averaged to 30-40\%, was found at $\mathrm{t} 20 \mathrm{~min}$ with almost all molecular species $(52.4 ; 52.3 ; 52.2 ; 54.6,54.5$ and 54.4), except for TAGs 52.5 and 54.7 which exhibited increasing levels. With all others, a subsequent regeneration to the t0 levels occurred. TAGs in maize RTb samples still fluctuated but in a different manner. The main molecular species 52.4 and 54.6, for instance, had a tendency to increase during the first $30 \mathrm{~min}$, while decreased later. To the end of the incubation after $60 \mathrm{~min}$, both molecular species reached at least the level of t0 samples, in case of 54.6 higher ones.

In Abutilon RTa samples, a strong fluctuation of TAG molecular species was recorded with the 52.4, 52.3, 54.7, in particular with the 54.6, 54.5, 54.4 and 54.3 molecular species. The losses were highest in the 54.5 and 54.4 species (up to $50 \%$ and more). In the AbRTb samples, similar fluctuation patterns were found, with increases after 50 min in AbRTb samples, compared to shorter incubation times. TAG 54.6 and 54.5 decreased during the first $20 \mathrm{~min}$. For most of the molecular species, the t0 levels were not reached again after $1 \mathrm{~h}$, in contrast to maize RTa samples. TAG levels in most of the t0 samples of the RTa series were often higher than the ones found during the incubation, which may indicate that TAG levels decreased already very early during the incubation. The up and downs in the TAG profiles may be related to different and cascaded organized regeneration sites.

In maize RTa sample series, no alterations in the amounts of diacylglycerol (DAG) were found. In the ZmRTb sample series, DAGs, expect for molecular species 18:2/18:2 at $40 \mathrm{~min}$, were not significantly altered, although there was a tendency for reduction between 30-50 min. In the Abutilon RTa samples, the main DAGs showed slightly reduced levels during the early course of the incubation, but recovered later. In the older root part, an increase of the levels between 10 to 50 min was found for the DAGs 16:0/18:3 and 16:0/18:2. In most of the Abutilon samples, DAG t0 levels were higher, however predominantly without significance. For both species, DAGs were less affected than TAGs. Since DAGs of Abutilon roots exhibited some responsiveness, PA values were here determined. PA amounts were only enhanced after $20 \mathrm{~min}$ in series a, and after $10 \mathrm{~min}$ in series b, otherwise not significantly affected (Fig.10; Fig. S2). The lipid analyses disclosed 1) an early decrease of defined membrane phospholipids, from which PI in Abutilon and PC in maize are most affected with defined molecular species. 2) The highest response was ascertained for total fatty acids, particularly the decrease of UFA 18:2 in 
the youngest tissue in both species. UFA 18:3, not affected in ZmRTa samples, increased in ZmRTb samples, but considerably decreased in both Abutilon series. Palmitic acid was only reduced in Abutilon. 3) Regarding the neutral lipids, TAGs were affected in both species, but DAGs were almost not changed in maize, and in Abutilon to a much lower degree than TAGs.

4) Disturbances of membrane PL contents were rapidly balanced in young root tissue of both species. The data indicate a) different PLs with defined molecular species as major targets for BOA-6-OH damage and b) differences in membrane repair of maize and Abutilon.

\section{Gene Expression in Maize Root Tips}

Gene expression studies were performed by qRT-PCR to unravel whether the oxidative stress or the changes in lipid composition were based on transcriptional regulation. The expression of SOD2 was upregulated in the root tip when the seedlings were exposed to the BOA-OHs, shown in Fig. 11 for the $30 \mathrm{~min}$ to $6 \mathrm{~h}$ incubation period. Except for BOA-7-OH, all isomers elicited a 6-7fold higher SOD2 expression after $30 \mathrm{~min}$ of incubation. The high levels were maintained over a period of $6 \mathrm{~h}$, then dropped to $4-4.5$ fold after $24 \mathrm{~h}$. With BOA-7-OH, a retarded increase to similar extend was found (6.5fold after $24 \mathrm{~h})$.

The FAD2-2 gene expression during BOA-6-OH exposure was increased after 30 min by 23.7 fold and maintained at this level for at least $6 \mathrm{~h}$. The up regulation of FAD2-2 expression was higher with the other BOA-OH isomers and reached a 7 fold expression after $6 \mathrm{~h}$ (BOA-5$\mathrm{OH}, \mathrm{BOA}-4-\mathrm{OH}$ ), and a 5 fold expression with $\mathrm{BOA}-7-\mathrm{OH}$, thus these isomers may cause a more severe lipid damage. In contrast, FAD2-1 was almost not responsive, similar to CAT1. CAT3 expression was not enhanced with BOA-4-OH, but it was increased with BOA-5/6-OH, by 2 fold, and 2.4 fold after $6 \mathrm{~h}$. An almost 3 fold increase was found after $6 \mathrm{~h}$ with BOA-7-OH. $N P R 1$ and POX12, two genes involved in regulation of pathogenesis and resistance, were not responsive. $P R 4$ was about 1.7 -fold up regulated after a $6 \mathrm{~h}$ exposure to $\mathrm{BOA}-6-\mathrm{OH}$ and 2.6 fold after BOA-5-OH. PRI was up regulated after $24 \mathrm{~h}$ in presence of BOA-4-OH (1.8fold) and of BOA-7-OH (3.2fold). Thus, the expression profiles of CAT3, PR4 and PR1 seem to be specific for isomers and perhaps for the concentration and presumably dependent on the duration of exposure.

\section{Accumulation of BOA-OH Detoxification Products}

Maize seedlings started to glucosylate BOA-6-OH almost immediately when exposed to the compound. Within $10 \mathrm{~min}$, about $100 \mathrm{nmol} / \mathrm{g} \mathrm{FW}$ of the glucosides were produced in the root 
tips. The amounts of the detoxification product increased constantly further on, reaching about $500 \mathrm{nmol} / \mathrm{g} \mathrm{FW}$ within $1 \mathrm{~h}$.

For long term accumulation of detoxification products, also the other isomers were tested. Within $24 \mathrm{~h}, \sim 5 \mu \mathrm{mol} / \mathrm{g}$ FW BOA-6-O-glucoside and $\sim 3 \mu \mathrm{mol}$ BOA-5-O-glucoside accumulated in the roots, but only traces of not further analyzed BOA-4-OH and BOA-7-OH detoxification products (Fig. 12). The fast glucosylation of BOA-6-OH, concomitant with ROS elimination, is supposed to be essential for blocking continued membrane damage, thereby explaining the lower up-regulation of FAD2-2. Analyses of the incubation media after $24 \mathrm{~h}$ revealed a strong decrease of $\mathrm{BOA}-6-\mathrm{OH}$ and $\mathrm{BOA}-5-\mathrm{OH}$ to about $5 \%$ and $9 \%$ of the original amounts, and also of BOA-4-OH (3\%) and $\mathrm{BOA}-7-\mathrm{OH}(6 \%)$, indicating that additional mechanisms contribute to the compounds' detoxification or elimination by polymerization. The position of the $\mathrm{OH}$ group strongly influenced the detoxification via glucosylation.

\section{DISCUSSION}

\section{Root Zone Dependent Reactions}

The early defense strategy against allelopathic BOA-OHs encompasses contemporaneous ROS and $\mathrm{BOA}-\mathrm{OH}$ detoxification and lipid regeneration in the youngest root zones of maize seedlings whereas older root zones with emerged lateral roots predominantly performed compound polymerizations at the surface. Root colonizing microorganisms contribute to ROS detoxification by catalase activity. The density of microbial colonization and the species diversity within established microbiomes are described to be root zone dependent (Massalha et al. 2017; Schmidt et al. 2018; Rüger et al. 2021). While some microbial species prefer the root tip, others colonize mainly the root hairs or emergence sites of lateral roots. The abundance of some species in mature assemblies increases from the zone of cell division to the mature part with increasing plant age. Moreover, the colonization density at the root tip is strongly influenced by environmental conditions. Nitrate highly increases the colonization at the root tip and root hairs (DeAngelis et al. 2005). Variations in the species composition on root surfaces are also heavily influenced by the soil. For instance, colonization of Abutilon seeds with a natural Actinomucor elegans consortium depends on the soil microbiome of the cultivation site. Seedlings grown from these seeds developed another detoxification behavior for BOA-OHs (Schulz et al. 2017). Root hair colonizing microorganisms, such as beneficial Pseudomonas 
species, are known from Arabidopsis, rice, tomato and maize (Prieto et al. 2011), and many of these microorganisms possess catalases (Kim and Park 2014). The different reactions towards BOA-OH isomers depend therefore on root zone characteristics in combination with responses of defined microorganisms that may shield the root from fatal allelochemical injuries. Until these mechanisms come into effect, minimization of cellular damage requires further, plant specific defense reactions, in particular in the vulnerable root tips which have not yet mature microbial assemblies, well-coordinated in their functions.

Aside from polymerizations or glucosylations, elimination of the BOA isomers may probably occur by additional mechanisms. Although radical scavenger functions of many phenolic compounds are a common assumption, mixtures of exogenous phenolics have been found to elicit an oxidative burst-like reaction (Baker et al. 2005; O'Brien et al. 2012).

Benzoxazinoids released from root hairs and applied BOA-OHs may undergo co-oxidation, which can result in compound destruction. This mechanism could contribute to BOA-OH elimination and may explain the strong reduction of $\mathrm{BOA}-\mathrm{OH}$ contents from the mediums after 24h incubations. Perhaps, root hairs and maize root tips are therefore not covered with polymer coats.

\section{Maize Gene Inductions, BOA-OH Glucosylation, Lipid Damage and Repair}

BOA-OH isomers elicited a fast relative increase of SOD2 transcripts in maize root tips for superoxide anion radical detoxification. SOD2 expression was upregulated within $30 \mathrm{~min}$ by all BOA-OH isomers, indicative for a fast elevation of the ROS levels in the young root cells. The alteration of relative $S O D 2$ transcript abundance is much faster than found in maize cultivars infested with aphids, which led to a transcript elevation from 1.3 to 5.4 fold after 4 to $8 \mathrm{~h}$ (Sytykiewicz 2014). SOD2 gene induction is also responsive to paraquat and the allelochemical juglone (Gail et al. 1986).

Whereas CAT1 transcript abundance was not changed, CAT3 gene expression was weakly enhanced (2-3fold) after $6 \mathrm{~h}$ incubation with the BOA-OH isomers, except for BOA-4-OH. The induction of $C A T 3$ gene expression was congruent with a weak bubble development at the root tip surface after $6 \mathrm{~h}$ of incubation with BOA-6-OH. In juglone treated germinating maize kernels, none of the catalase genes was induced after $24 \mathrm{~h}$, even when $1 \mathrm{mM}$ juglone was applied. An increase in catalase activity after ferulic acid application was observed in maize roots but only with concentrations higher than 1mM (Rama Devi and Prasad 1996). CruzOrtega et al. (2002) found a more than 50\% decreased catalase activity in maize roots after exposure to an aqueous leachate of allelopathic Callicarpa acuminata. We waived 
measurements of catalase activity, because it is not possible to distinguish between plant and microbe derived activities in crude protein extracts. From our results we conclude that CAT1 is not, and CAT3 arguably integrated at a later stage of the detoxification process, but both enzymes do not seem to be responsible for the major $\mathrm{H}_{2} \mathrm{O}_{2}$ elimination during the first hours of BOA-OH exposures. We hypothesize that the major part of catalase activity is attributed to root colonizing microorganisms. Indeed, we can presently not exclude BOA-OH stressed microorganisms as the earliest and main producers of ROS, that enter root cells prior to catalase induction and which are mainly responsible for the almost immediate damage of membrane lipids in the youngest root tissue.

SOD2 gene expression is concomitant with elevated expression of desaturase FAD2-2. FAD22 is the major oleoyl desaturase responsible for the synthesis of linoleic acid, a constituent of plant membranes (Hernández et al. 2009), thus the ER membrane bound FAD2-2 enzyme is essentially important for the regeneration of the linoleic acid (18:2) pools in maize root tips after BOA-OH exposure. Linoleic acid is the most affected UFA during BOA-6-OH incubations. FAD2 and FAD3 (not measured) are primarily responsible for the desaturation of extra-chloroplastic phospholipids. They may particularly contribute to fast membrane repair. FAD2 converts oleate bond to phosphatidylcholine into linoleate by introducing a second double bond at the $\mathrm{C} 12$ position. Whereas it is known that cold stress induces enhancement of the FAD2-2 gene expression for membrane adaptation (Dar et al. 2017), we could not find reports on FAD2-2 transcript enhancement caused by chemical stress. FAD2-1 and FAD2-2 are isogenes and their expression is differently regulated, as concluded from their co-expression networks with different transcription factors in maize (Zhao et al. 2019), which may orchestrate their responsiveness to (allelo)chemical stress.

Clearly, BOA-OH isomers elicit ROS and damage of membrane lipids. Ingólfsson et al. (2014) emphasized cell membrane perturbations by altered bilayer properties due to phenolic phytochemicals getting attached to the bilayer/solution interface. The compounds merge to the membrane by hydrophobic interaction, resulting in softened, partitioned phospholipid bilayers that influence membrane proteins functions and activities. Bilayer destabilization and alteration of membrane fluidity, also found for the allelochemical sorgoleone (Lebecque et al. 2019), are the consequences, not only in plants but probably also in microbial membranes. We hypothesize that these perturbations activate lipases and perhaps lipoxygenases to remove affected fatty acids from membrane phospholipids for fatty acid exchange and reestablishing correct membrane functioning. Presumably, the removal of fatty acids that are in contact with BOA$6 / 5-\mathrm{OH}$ is closely linked to the glucosylation step for detoxification which may present a 
prerequisite for membrane repair. The presence of UGT for glucosylation already in the cell wall, as was found for maize UGT BX9, is reasonable for protecting the plasma membrane first, having higher contents of unsaturated phospholipids in the cytosolic leaflet, and later other membranes in the cell. Since BOA-4-OH and BOA-7-OH do not accumulate as glucosides, and BOA-5-OH to a lower degree, oxidative stress and membrane damage may be higher with these isomers, while the effects of BOA-7-OH are retarded due to the low solubility. In addition, maize may be adopted to the occurrence of BOA-6-OH in the cell wall.

TAGs seem to be affected mainly in the youngest root part in both plant species, but due to the strong variations during the course of incubation, it is presently difficult to interpret the role of BOA-6-OH on TAGs. In maize, only the contents of a few molecular species were changed, in contrast to Abutilon. The most abundant molecular species 56:4 is affected in both species, while others show a weaker response.

As mentioned above, TAGs, which are compartmented in lipid droplets, serve mainly as storage compounds. In vegetative tissues and under normal growth conditions, only few lipid droplets are found, while during stress conditions, such as drought, the amounts of TAGs are increased. In plants and animals, the increase in TAG production is generally considered as a detoxification reaction to lower the concentrations of free fatty acids to avoid lipotoxicity (Piccolis et al. 2019). An increase of lipid droplets and TAGs is described to occur during long term adverse conditions elicited by nutrient, light, heat, cold and salt stresses. Here, it can be hypothesized that fatty acids can be released from TAGs for membrane lipid repair, and TAGs may have a role in maintaining fatty acid homeostasis. TAGs from lipid droplets are thought to function as precursors for membrane re-synthesis (Lee et al. 2020). In yeast, storage lipid synthesis and membrane biogenesis have been described to be coordinated (Gaspar et al. 2011). TAGs may be released also for energy homeostasis during metabolic conditions demanding high energy inputs, such as stress conditions. A decrease in TAGs to raise the energy costs necessary for counteracting membrane and other damages, elicited by allelochemicals of the dinoflagellate Alexandrium minutum, was also reported for the diatom Chaetoceros muelleri (Long et al. 2018). According to our results, TAGs may function in this way in short term BOA$\mathrm{OH}$ stressed maize and Abutilon root tips, allowing a fast repair within 20 to $40 \mathrm{~min}$ of damaged structural phospholipids. DAGs, released from TAGs, could serve as building blocks for PE and PC synthesis (Henry et al. 2012). A dissection of the complex interactions and BOA-OH impacts on TAG metabolism clearly requires further investigations.

Regarding phospholipid alterations, we found differences between maize and Abutilon. Whereas in maize PC was the only phospholipid which was significantly reduced during the 
first $30 \mathrm{~min}$ in the youngest part of the root tip, PI was the most affected phospholipid in both Abutilon RTa and RTb samples. The decrease of PI could indicate a short-term activation of the phosphoinositide-specific phospholipase C signaling pathway, important for plant immunity (Vossen et al. 2010), which does not occur in maize. For verification, further studies are required. Also, other phospholipases are activated by $\mathrm{H}_{2} \mathrm{O}_{2}$, such as phospholipase D which releases phospholipid head groups (Yamaguchi et al. 2004). Since the membrane repair mechanisms in maize and Abutilon are highly efficient, further downstream events, for instance continuing release of signaling molecules, do not occur in critical amounts.

\section{Connection to immune response}

The efficient elimination of successive $\mathrm{H}_{2} \mathrm{O}_{2}$ by SOD2 and catalases together with the fast repair of membrane lipids should diminish further oxidation of C18 UFAs. Thus, an increase of lipoxidation end-products from UFA 18:3, leading to the jasmonate precursor 12oxophytodienoic acid (OPDA), might be suppressed in maize but perhaps not in Abutilon in a similar degree. According to Liu et al. (2016), genes related to ROS production and scavenging systems, for instance, catalase and superoxide dismutase, are not responsive to methyljasmonate treatment.

The oxidized fatty acid derivatives cis-OPDA and jasmonate have, however, a pivotal role in plant defense (Schenk and Schikora 2015). NPR1 has an important function in systemic acquired resistance (SAR) and induced systemic resistance (ISR) by triggering the cross talk between the salicylic acid (SA) and JA (Backer et al. 2019). The transcription of NPRI is positively influenced by the SA pathway that stimulates transcription of $P R 1, P R 2$ and $P R 5$, leading to systemic acquired resistance (SAR), (Ali et al. 2018). POX 12, belonging to the SA markers, is not induced. Expression of antifungal $P R 1$, as one member of this PR group, and NPR1 showed no noteworthy response elicited by BOA-5/6-OH isomers, but BOA-4-OH and BOA-7-OH induced a moderate up regulation after $24 \mathrm{~h}$. PR4, an antifungal chitinase II, enhances resistance against biotrophic and necrotrophic fungal phytopathogens. PR4 transcription is up regulated by the JA defense signaling pathway which activates local acquired resistance (LAR). Only BOA-6-OH and BOA-5-OH led to a low enhancement of PR4 expression after $6 \mathrm{~h}$, indicating that linolenic acid derivatives could be too low to stimulate the JA defense signaling pathway efficiently. We believe that JA precursors from nonenzymatic peroxidation of linolenic acid do not accumulate in sufficient amounts to trigger plant defense reactions considerably. On the other hand, cleavage of linoleic acid (18:2) or linolenic acid (18:3) from membrane lipids can submit to pathways resulting in so-called death acids 
(Christensen et al. 2015), which have also special roles in defense and stress responses. According to our results, membrane damage by the allelochemicals may be eventually linked to key events important for plant immune responses after long term application.

\section{ACKNOWLEDGEMENT}

The authors thank Ulrich Disko, Forschungszentrum Jülich $\mathrm{GmbH}$, for technical assistance with electrospray ionization-mass spectrometry (UPLC-ESI-MS) and performance of measurements. We thank Helga Peisker (University of Bonn) for lipid measurements, quantification by direct infusion-nanospray-mass spectrometry and further technical assistance. This paper is dedicated to our colleague and friend Dr. Lothar Hennig, who has been an engaged analytical chemist in our team for more than 20 years, and so in this investigation during which he passed away. We thank the KWS Saat (Einbeck, Germany) for supporting us with the maize cultivar Cassila.

\section{AUTHOR INFORMATION}

Affiliations

IMBIO Institute of Molecular Physiology and Biotechnology of Plants, University of Bonn, Karlrobert-Kreiten Str. 13, 53115 Bonn, Germany

Institut für Organische Chemie, Universität Leipzig, Johannisallee 29, 04103 Leipzig, Germany IBG-3: Agrosphäre, Forschungszentrum Jülich GmbH, Jülich, Germany

Laura Laschke, Vadim Schütz, Oliver Schackow, Dieter Sicker, Lothar Hennig, Diana Hofmann, Peter Dörmann and Margot Schulz

\section{CORRESPONDING AUTHOR}

Correspondence to Margot Schulz

\section{DECLARATIONS}

\section{Funding}

No funding was received for conducting this study

\section{Conflicts of interest}

The authors declare no competing interest. The authors have no relevant financial or nonfinancial interests to disclose. 


\section{ETHICS DECLARATIONS}

\section{Ethical Approval}

Not applicable.

\section{Consent to Participate}

Not applicable.

\section{Consent for Publication}

All authors have read and accepted the final version of this manuscript.

\section{Data Availability}

Data sets for archives were not generated. The data sets generated during and/or analysed during the current study are available from the corresponding author.

\section{Code Availability}

Not applicable.

\section{Author's distribution}

M.S. designed research and performed root hair experiments; O.S. and D.S. synthesized BOAOHs; D.S, L.H. D.H with U.D. analyzed compound structures. L.L. and V.S. performed lipid extraction, lipid sample preparation and qPCR; P.D. with H.P. performed lipid analyses. V.S. and M.S. did further research and analyzed data. M.S. and D.S. wrote the paper.

\section{REFERENCES}

Ali S, Ganai BA, Kamili AN, Bhat AA, Mir ZA, Bhat JA, Tyagi A, Islam ST, Mushtaq M, Yadav P, Rawat S, Grover A (2018) Pathogenesis-related proteins and peptides as promising tools for engineering plants with multiple stress tolerance. Microbiol Res 212-213: 29-37. https://doi.org/10.1016/j.micres.2018.04.008

Backer R, Naidoo S, van den Berg N (2019) The nonexpressor of pathogenesis-related genes 1 (NPR1) and related family: Mechanistic insights in plant disease resistance. Front Plant Sci 10:102. https://doi: 10.3389/fpls.2019.00102

Barclay KD, McKersie BD (1994) Peroxidation reactions in plant membranes: Effects of free fatty acids. Lipids 29: 877-882 
Batish D, Singh N, Setia N, Kaur S, Kohl R (2006) 2-Benzoxazolinone (BOA) induced oxidative stress, lipid peroxidation and changes in some antioxidant enzyme activities in mung bean (Phaseolus aureus). Plant Physiol Biochem 44: 819-827. https://doi.org/10.1016/j.plaphy.2006.10.014

Baxter A, Mittler R, Suzuki N (2014) ROS as key players in plant stress signalling. J Exp Bot 65:1229-1240. https://doi: 10.1093/jxb/ert375

Baker CJ, Roberts DP, Mock NM, Whitaker BD, Deahl KL, Aver'yanov AA (2005) Apoplastic redox metabolism: Synergistic phenolic oxidation and a novel oxidative burst. Publications from USDA-ARS/UNL Faculty. 337. https://digitalcommons.unl.edu/usdaarsfacpub/337

Berestovoy MA, Pavlenko OS, Goldenkova-Pavlova IV (2020) Plant fatty acid desaturases: Role in the life of plants and biotechnological potential. Biol Bul Rev 10: 127-139. https://doi.org/10.1134/S2079086420020024

Bohn M, Heinz E, Luthje S (2001) Lipid composition and fluidity of plasma membranes isolated from corn (Zea mays L.) roots. Arch Biochem Biophys 387: 35-40. https://doi: 10.1016/j.jplph.2005.12.008

Boselli R, Anders N, Fiorini A, Ganimede C, Faccini N, Marocco A, Schulz M, Tabaglio V (2021) Improving weed control in sustainable agro-ecosystems: role of cultivar and termination timing of rye cover crop. IJA (AOP). https://doi.org/10.4081/ija.2021.1807

Bravo A, Brands M, Wewer V, Dörmann P, Harrison MJ (2017), Arbuscular mycorrhizaspecific enzymes FatM and RAM2 fine-tune lipid biosynthesis to promote development of arbuscular mycorrhiza. New Phytol 214: 1631-1645. https://doi.org/10.1111/nph.14533

Browse J, McCourt PJ, Somerville CR (1986) Fatty acid composition of leaf lipids determined after combined digestion and fatty acid methyl ester formation from fresh tissue. Anal Biochem 152:141-145

Cacas J-L, Buré C, Grosjean K et al. (2016) Revisiting plant plasma membrane lipids in tobacco: A focus on sphingolipids. Plant Physiol 170: 367-384. https://doi:10.1104/ pp.15.00564

Christensen SA, Huffaker A, Kaplan F, et al. (2015) Cyclopentenone-mediated death and defense in maize. PNAS 112: 11407-11412. https://doi: 10.1073/pnas.1511131112 
Cruz-Ortega R, Ayala-Cordero G, Anaya AL (2002) Allelochemical stress produced by the aqueous leachate of Callicarpa acuminata: Effects on roots of bean, maize, and tomato. Physiol Plant 116: 20-27. https://doi: 10.1034/j.1399-3054.2002.1160103.x

Dar AA, Choudhury AR, Kancharla PK, Arumugam N (2017) The FAD2 gene in plants: occurrence, regulation, and role. Front Plant Sc. 8:1789. https://doi: 10.3389/fpls.2017.01789

DeAngelis KM, Ji P, Firestone MK, Lindow SE (2005) Two novel bacterial biosensors for detection of nitrate availability in the rhizosphere. Appl Environ Microbiol. 2005;71(12):85378547. https://doi:10.1128/AEM.71.12.8537-8547.2005

Debona D, Rodrigues FA, Rios JA, Nascimento KJT (2012) Biochemical changes in the leaves of wheat plants infected by Pyricularia oryzae. Phytopathol 102. https://doi:org/10. 1094/PHYTO-06-12-0125-R

Edwards JA, Santos-Medellın CM, Liechty ZS, Nguyen B, Lurie E, Eason S, et al. (2018) Compositional shifts in root-associated bacterial and archaeal microbiota track the plant life cycle in field-grown rice. PLoS Biol 16: e2003862. https://doi.org/10.1371/journal .pbio. 2003862

Einhellig FA, Putnam AR, Tang CS (1986) Mechanisms and modes of action of allelochemicals. The Science of Allelopathy 1986; New York John Wiley and Sons Elbs K (1893) Ueber Nitrohydrochinon. J Prakt Chem 48: 179-185

Gail L, Matters J, Scandalios G (1986) Effect of the free radical-generating herbicide paraquat on the expression of the superoxide dismutase (Sod) genes in maize. Biochim Biophys Acta 882: 29-38. https://doi.org/10.1016/0304-4165(86)90051-6

Gaspar M L, Hofbauer HF, Kohlwein SD, Henry SA (2011) Coordination of storage lipid synthesis and membrane biogenesis: evidence for cross-talk between triacylglycerol metabolism and phosphatidylinositol synthesis. J Biol Chem 286: 1696-1708. https://doi.org/ 10.1074/jbc.M110.172296

Gasulla F, vom Dorp K, Dombrink I, Zähringer U, Gisch N, Dörmann P, Bartels D (2013) The role of lipid metabolism in the acquisition of desiccation-tolerance in Craterostigma plantagineum. A comparative approach. Plant J 75: 726-741. https://doi.org/10.1111/tpj.12241 Gond SK, Bergen MS, Torres MS, White JF Jr (2015) Endophytic Bacillus spp. produce antifungal lipopeptides and induce host defense gene expression in maize. Microbiol Res. 172:79-87. https://doi: 10.1016/j.micres.2014.11.004. Epub 2014 Nov 28 
Gniazdowska, A, Bogatek, R (2005) Allelopathic interactions between plants. Multisite action of allelochemicals. Acta Physiol Plant 27: 395-407. https://doi.org/10.1007/s11738-005-00173

Haghi Kia S, Schulz M, Ayah E, Schouten A, Müllenborn C, Paetz C, Schneider B, Hofmann D, Disko U, Tabaglio V, Marocco A (2014) Abutilon theophrasti's defense against the allelochemical benzoxazolin-2(3H)-one: Support by Actinomucor elegans. J Chem Ecol 40: 1286-1298. https://doi.org/10.1007/s10886-014-0529-7

Hemetsberger C, Herrberger C, Zechmann B, Hillmer M, Doehlemann G (2012) The Ustilago maydis effector Pep1 suppresses plant immunity by inhibition of host peroxidase activity. PLoS Pathog 8(5): e1002684. https://doi: 10.1371/journal.ppat.1002684

Henry SA, Kohlwein SD, Carman GM (2012) Metabolism and regulation of glycerolipids in the yeast Saccharomyces cerevisiae. Genetics 190:317-349. https://doi:10.1534/ genetics.111.130286

Hernández ML, Padilla MN, Mancha M, Martínez-Rivas JM (2009) Expression analysis identifies $F A D 2-2$ as the olive oleate desaturase gene mainly responsible for the linoleic acid content in virgin olive oil. J Agri Food Chem 57: 6199 -6206. https://doi: 10.1021/jf900678z

Hofmann D, Knop M, Hao H, Hennig L, Sicker D, Schulz M (2006). Glucosides from MBOA and BOA detoxification by Zea mays and Portulaca oleracea. J Nat Prod 69: 34-37. https://doi: $10.1021 / \mathrm{np} 0580762$

Hu L, Robert CAM, Cadot S et al. (2018) Root exudate metabolites drive plant-soil feedbacks on growth and defense by shaping the rhizosphere microbiota. Nat Com 9: 2738 https://doi.org/10.1038/s41467-018-05122-7

Huang CZ, Xu L, Jin-Jing S., Zhang ZH, FU ML, Teng H-Y, Yi K-K (2020) Allelochemical phydroxybenzoic acid inhibits root growth via regulating ROS accumulation in cucumber (Cucumis sativus L.) J Integr Agric 19: 518-527. https://doi.org/10.1016/S20953119(19)62781-4

Huo C, An D, Wang B, Yuying Z, Lin W (2005). Structure elucidation and complete NMR spectral assignments of a new benzoxazolinone-glucoside from Acanthus ilicifolius. MRC 43: 343-345 
Ingólfssson HI, Thakur P, Herold KF, Hobart EA, Ramsey N B, Periole X, et al. (2014) Phytochemicals perturb membranes and promiscuously alter protein function. ACS Chem Biol 9: 1788-1798. https://doi: 10.1021/cb500086e

Kauffmann H, Kugel W (1911) Über das 4-Nitro-resorcin. Ber Dtsch Chem Ges 44: 753-756.

Kim J, Park W (2014) Oxidative stress response in Pseudomonas putida. Appl Microbiol Biotechnol 98: 6933-6946. https://doi.org/10.1007/s00253-014-5883-4

Lara-Nuñez A, Romero-Romero T, Ventura JL, Blanca V, Anaya SL, Cruz-Ortega R (2006) Allelochemical stress causes inhibition of growth and oxidative damage in Lycopersicon esculentum Mill. Plant Cell Environ 29: 2009-2016. https://doi.org/10.1111/j.13653040.2006.01575.x

Lebecque S, Lins L, Dayan FE, Fauconnier ML, Deleu M (2019) Interactions between natural herbicides and lipid bilayers mimicking the plant plasma membrane. Front Plant Sci 18: 10:329. https:// doi:10.3389/fpls.2019.00329

Lee J, Salsman J, Foster J, Dellaire G, Ridgway ND (2020) LAPS regulate lipid metabolism. Life Sci Alliance 3 (8) e202000751; https://doi:10.26508/lsa.202000751

Lins L, Dal Maso S, Foncoux B, Kamili A, Laurin Y, Genva M, Jijakli MH, De Clerck C, Fauconnier ML, Deleu M (2019) Insights into the Relationships Between Herbicide Activities, Molecular Structure and Membrane Interaction of Cinnamon and Citronella Essential Oils Components. Int J Mol Sci 20:4007. https://doi.org/10.3390/ijms20164007

Liszkay A, van der Zalm E, Schopfer P (2004) Production of reactive oxygen intermediates by maize roots and their role in wall loosening and elongation growth. Plant Physiol 136: 31143123. http://dx.doi.org/10.1104/pp.104.044784

Liu H, Costa L, Carvalhais, CK, Schenk PM (2016) Development of marker genes for jasmonic acid signaling in shoots and roots of wheat, Plant Sign Behav 11:5, e1176654. https://doi:10.1080/15592324.2016.1176654

Long M, Tallec K, Soudant P, Le Grand F, Donval A, Lambert C, Sarthou G, Jolley DF, Hégaret H (2018) Allelochemicals from Alexandrium minutum induce rapid inhibition of metabolism and modify the membranes from Chaetoceros muelleri. Algal Res 35: 508-518. https://doi.org/10.1016/j.algal.2018.09.023 
Lu J, Xu Y, Wang J, Singer SD, Chen G (2020) The role of triacylglycerol in plant stress response. Plants 8:472. https://doi:10.3390/plants9040472

Maag D, Köhler A, Robert CAM, Frey M, Wolfender J-L, Turlings TCJ, Glauser G, Erb M (2016) Highly localized and persistent induction of $B x l$-dependent herbivore resistance factors in maize. Plant J 88: 976-991. https://doi:10.1111/tpj.13308

Macias FA, Oliveros-Bastidas A, Marin D, Castellano D, Simonet AM, Molinillo JMG (2005) Degradation studies on benzoxazinoids. Soil degradation dynamics of (2R)-2-B-Dglucopyranosyl-4-hydroxy(2H)-1,4-phenoxazin-3-(4H)-one (DIBOA-Glc) and its degradation products, phytotoxic allelochemicals from Gramineae. J Agric Food Chem 53:538-548. https://doi.org/10.1021/jf0484071

Maffei M, Camuso W, Sacco S (2001) Effect of Mentha x piperita essential oil and monoterpenes on cucumber membrane potential. Phytochemistry 58: 703-707. https://doi.org/10.1016/S0031-9422(01)00313-2

Marino D, Dunand C, Puppo A, Pauly N (2012) A burst of plant NADPH oxidases. Trends Plant Sci 17: 9-15. https://doi.org/10.1016/j.tplants.2011.10.001

Massalha H, Korenblum E, Malitsky S, Shapiro OH, Aharoni A (2017) Live imaging of rootbacteria interactions in a microfluidics setup. Proc Natl Acad Sci USA 14: 4549-4554. https://doi: 10.1073/pnas.1618584114

Michaud M, Prinz WA, Jouhet J (2017) Glycerolipid synthesis and lipid trafficking in plant mitochondria. FEBS J 284: 376-390. https://doi.org/10.1111/febs.13812

Nestler J, Scheutz W, Hochholdinger F (2011) Conserved and unique features of the maize (Zea mays L.) root hair proteome. J Proteome Res 10: 2525-2537. https:// doi.org/10.1021/ pr200003k

Niculaes C, Abramov A, Hannemann L, Frey M (2018) Plant protection by benzoxazinoids Recent insights into biosynthesis and function. Agronomy 8: 143. https://doi:org/10.3390/ agronomy 8080143

Niemeyer H M (2009). Hydroxamic acids derived from 2-hydroxy-2h-1,4-benzoxazin-3(4H) one: Key defense chemicals of cereals. J Agric Food Chem 57: 1677-1696. https://doi: 10.1021/jf8034034 
Mylona PV, Polidoros AN, Scandalios JG (2007) Antioxidant gene responses to ROSgenerating xenobiotics in developing and germinated scutella of maize. J Exp Bot 58: 13011312, https://doi.org/10.1093/jxb/erl292

Neal AL, Ahmad S, Gordon-Weeks R, Ton J (2012) Benzoxazinoids in root exudates of maize attract Pseudomonas putida to the rhizosphere. PLoS ONE 7(4): e35498. https://doi: 10.1371/journal.pone.0035498

O'Brien JA, Daudi A, Butt VS, Bolwell GP (2012) Reactive oxygen species and their role in plant defense and cell wall metabolism. Planta 236:765-79. https://doi:10.1007/s00425-012$1696-9$

Orman-Ligeza B, Parizot B, de Rycke R, Fernandez A, Himschoot E, Van Breusegem F, Bennett MJ, Périlleux C, Beeckman T, Draye X (2016) RBOH-mediated ROS production facilitates lateral root emergence in Arabidopsis. Development 143: 3328-3339. https:/ /doi:10.1242/dev.136465

Park WJ, Hochholdinger F, Gierl A (2004) Release of defense molecules the benzoxazinoids during lateral- and crown root emergence in Zea mays. J Plant Physiol 161: 981985. https://doi.org/10.1016/j.jplph.2004.01.005

Piccolis M, Bond L, Kampmann M, Weissmann J, Walther T, Farese R (2019) Probing the global cellular responses to lipotoxicity caused by saturated fatty acids. Molec Cell 4 . https://doi: 10.1016/j.molcel.2019.01.036

Planchamp C, Glauser G, Mauch-Mani B (2015) Root inoculation with Pseudomonas putida KT2440 induces transcriptional and metabolic changes and systemic resistance in maize plants. Front Plant Sci 5: 719. https://doi:10.3389/fpls.2014.00719

Prieto P, Schilirò E, Maldonado-González MM, et al. (2011) Root hairs play a key role in the endophytic colonization of olive roots by Pseudomonas spp. with biocontrol activity. Microb Ecol 62: 435-445. https://doi.org/10.1007/s00248-011-9827-6

Rama DS, Prasad MNV (1996) Ferulic acid mediated changes in oxidative enzymes of maize seedlings: implications in growth. Biol Plant 38: 387. https://doi.org/10.1007/BF02896668

Redinbaugh MG, Sabre M, Scandalios JG (1990) The distribution of catalase activity, isozyme protein, and transcript in the tissues of the developing maize seedling. Plant Physiol 92:375380. https://doi:10.1104/pp.92.2.375 
Rosenblatt DH, Epstein J, Levitch M (1953) Some nuclearly substituted catechols and their acid dissociation constants. J Am Chem Soc 75: 3277-3278

Rüger L, Fenh K, Dumark K et al. (2021) Assembly patterns of the rhizosphere microbiome along the longitudinal root axis of maize (Zea mays L.). Front Microbiol 12:614501. https://doi:103389/fmicb.2021.614501

Sajad A, Ganai BA, Kamili AN et al. (2018) Pathogenesis-related proteins and peptides as promising tools for engineering plants with multiple stress tolerance. Microbiol Res 212-213: 29-37. https://doi.org/10.1016/j.micres.2018.04.008

Samajdar S, Becker EF, Banik K (2000) Surface-mediated highly efficient regioselective nitration of aromatic compounds by bismuth nitrate. Tetrahedron Lett 41: 8017-8020.

Sanchez-Moreiras AM, Reigosa MJ (2005) Whole plant response of lettuce after root exposure to BOA (2(3H)-benzoxazoninone). J Chem Ecol 31:2689-2703. https://doi.org/10.1007/s 10886-005-7620-z

Scandalios JG, Tsaftaris AS, Chandlee JM, Skadsen RW (1983) Expression of the developmentally regulated catalase (cat) genes in maize. Dev Genet 4: 281-293. https://doi.org/10.1002/dvg.1020040406

Schaffrath RE (1970) The synthesis of 2-nitroresorcinol: An experiment with sulfonic acids. J Chem Educ 47: 224-225

Schellhorn HE, Stones VL (1992) Regulation of katF and catE in Echerichia coli K-12 by weak acids. J Bacteriol 174: 4769-4776. https://doi.org/10.1128/jb.174.14.4769-4776.1992

Schenk ST, Schikora A (2015) AHL-priming functions via oxylipin and salicylic acid. Front Plant Sci 5: 784. https://doi:10.3389/fpls.2014.00784

Siebers M, Dörmann P, Hölzl G (2015) Membrane remodelling in phosphorus-deficient plants. In: Annual Plant Reviews Volume 48 (eds W.C. Plaxton and H. Lambers). https://doi.org/10.1002/9781118958841.ch9

Schmidt H, Nunan N, Höck A, Eickhorst T, Kaiser C, Woebken D, Raynaud X (2018) Recognizing patterns: Spatial analysis of observed microbial colonization on root surfaces. Front Environ Sci 6:61. https://doi: 10.3389/fenvs.2018.00061

Stark G (2005) Functional consequences of oxidative membrane damage. J Membrane Biol 205: 1-16. https://doi.org/10.1007/s00232-005-0753-8G 
Schütz V, Bigler L, Girel S, Laschke L, Sicker D, Schulz M (2019) Conversions of benzoxazinoids and downstream metabolites by soil microorganisms. Front Ecol Evol 7: 39. https://doi:10.3389/fevo.2019.00238

Schulz M, Marocco A, Tabaglio V (2012) BOA detoxification of four summer weeds during germination and seedling growth. J Chem Ecol 38: 933-946. http://dx.doi.org/10.1007/s10886012-0136-4

Schulz M, Filary B, Kühn S, Colby T, Harzen A, Schmidt J, Sicker D, Hennig L, Hofmann D, Disko U, Anders N (2016) Benzoxazolinone detoxification by $N$-Glucosylation: The multicompartment- network of Zea mays L. Plant Signal Behav 11: e1119962. https://doi: $10.1080 / 15592324.2015 .1119962$

Schulz M, Sicker D, Schackow O, Hennig O, Yurkov A, Siebers M, Hofmann D, Disko U, Ganimede C, Mondani L, Tabaglio V, Marocco A (2018) Cross-cooperations of Abutilon theophrasti Medik. and root surface colonizing microorganisms disarm phytotoxic hydroxybenzoxazolin-2(3H)-ones. Plant Signal Behav 12(8) https://doi:10.1080/ 15592324. 2017. 1358843

Schulz M, Tabaglio V, Marocco A, Macias FA, Molinillo JMG (2013). Benzoxazinoids in rye allelopathy - from discovery to application in sustainable weed control and organic farming. $\mathbf{J}$ Chem Eco. 39: 154-174. https://doi:10.1007/s10886-013-0235-x

Schulz M, Wieland I (1999) Variations in metabolism of BOA among species in various field communities - biochemical evidence for co-evolutionary processes in plant communities? Chemoecology 9: 133-141. https://doi:10.1007/s000490050044

Sicker D, Facile A (1989) Synthesis of 6-methoxy-2-oxo-2,3-dihydrobenzoxazole. Synthesis 1989: $875-876$

Sicker D, Frey M, Schulz M, Gierl A (2000) Role of natural benzoxazinones in the survival strategies of plants, In: Jeong KW (ed) International Review of Cytology - A Survey of Cell Biology Vol. 198. Academic Press, pp 319-346. https://doi.org/10.1016/s0074-7696(00)980082

Sicker D, Hao H, Schulz M (2004) Benzoxazolin-2-(3H)-ones: Generation, effects and detoxification in the competition among plants. In: Macias FA, Galindo JCG, Molinillo JMG, 
Cutler HG (eds) Allelopathy: Chemistry and Mode of Action of Allelochemicals. CRC Press: Boca Raton, Florida, USA, pp 77-102

Sicker D. Schneider B, Hennig L, Knop M, Schulz M (2001) Glycoside carbamates from benzoxazolin-2(3H)-one detoxification in extracts and exudates of corn roots. Phytochemistry 58: 819-825. https://doi.org/10.1016/S0031-9422(01)00299-0

Sicker D, Schulz M (2002) Benzoxazinones in plants: occurrence, synthetic access and biological activity. In: Atta-ur-Raman (ed) Studies in Natural Product Chemistry 27. Bioactive Natural Products, Elsevier, Amsterdam; Part H, pp 185-23

Siebers M, Rohr T, Ventura M, Schütz V, Thies S, Kovacic F, et al. (2018) Disruption of microbial community composition and identification of plant growth promoting microorganisms after exposure of soil to rapeseed-derived glucosinolates. PLoSONE 13(7): e0200160. https://doi.org/10.1371/journal.pone.0200160

Sytykiewicz H (2014) Differential expression of superoxide dismutase genes in aphid-stressed maize (Zea mays L.) seedlings. PLoS One. 10;9(4): e94847. https://doi: 10.1371/journal.pone.0094847

Tabaglio V, Gavazzi C, Schulz M, Marocco A (2008) Alternative weed control using the allelopathic effect of natural benzoxazinoids from rye mulch. Agron Sustain Dev 28: 397-401. https://doi.org/10.1051/agro:2008004

Tjellström H, Hellgren LI, Wieslander A, Sandelius AS (2010), Lipid asymmetry in plant plasma membranes: phosphate deficiency-induced phospholipid replacement is restricted to the cytosolic leaflet. FASEB J 24: 1128-1138. https://doi.org/10.1096/fj.09-139410

Vermeer, JEM, van Wijk R, Goedhart J, Geldner N, Chory J, Gadella TWJ Jr, Teun Munnik T (2017) In vivo imaging of diacylglycerol at the cytoplasmic leaflet of plant membranes. Plant Cell Physiol 58: 1196-1207. https://doi.org/10.1093/pcp/pcx012

Vossen JH, Abd-El-Haliem A, Fradin EF et al. (2010) Identification of tomato phosphatidylinositol-specific phospholipase-C (PI-PLC) family members and the role of PLC4 and PLC6 in HR and disease resistance. Plant J 62: 224-239. https://doi.org/10.1111/j.1365313X.2010.04136.x

Wheelis M (2008) Principles of modern microbiology. Jones \& Bartlett Publishers, Inc., Sudbury, MA 
Wouters FC, Gershenzon J, Vassao DG (2016) Benzoxazinoids: Reactivity and modes of action of a versatile class of plant chemical defenses. J. Braz. Chem. Soc. 27, 1379-1397. https://doi: $10.5935 / 0103-5053.20160177$

Yamaguchi T, Tanabe S, Minami E, Shibuya N (2004) Activation of phospholipase D induced by hydrogen peroxide in suspension-cultured rice cells. Plant Cell Physiol 45: 12611270. https://doi.org/10.1093/pcp/pch150

Zhao X, Wei J, He L, Zhang Y, Zhao Y, Xu X, Wei Y, Ge S, Ding D, Liu M, Gao S, Xu J (2019) Identification of fatty acid desaturases in maize and their differential responses to low and high temperature. Genes 10:445. https://doi.org/10.3390/genes10060445

Zinner H, Wigert H (1960) Benzazole, XI. Amino-und Hydroxy-benzoxazolinone. Chem Ber 93: 1331-1339.

FIGURE CAPTIONS

Figure 1: Nitro precursors 1-4 synthesized as precursors for the hydroxy BOAs 5-8.

Figure 2: General Synthesis of the four isomeric hydroxy BOAs 5-8.

Figure 3: Root hairs (A) were cut and extracted. The extracts and washing solutions obtained from the root hair zone including the mucilage drop (B) were analyzed for benzoxazinoid contents. The extracts of cut root hair contain DIMBOA-glc, DIMBOA and MBOA $(n=12)$, the wash solution only DIMBOA and MBOA ( $\mathrm{n}=7)$ as major compounds.

Figure 4: A, D: Root surface peroxidase assay (ABTS) exposes youngest root zones, the tips covered by the root cap and the bases of emerging roots as sites of peroxidase activity. B: Left to right: control, and after $24 \mathrm{~h}$ incubation with BOA-4-OH, BOA-5-OH, BOA-6-OH, BOA-7$\mathrm{OH}$. Dark polymers derived from BOA-OHs precipitate at lateral root emerging sites but not at the surface of root hairs, or the tip, $\mathrm{C}$ : After $\mathrm{BOA}-\mathrm{OH}$ incubations, ring-like structures developed preferentially at root zones prior to lateral root emergency. D: Root tips and root caps are dark after assaying peroxidase with ABTS. E: Dark spots at the emerging sites of lateral roots after BOA-OH incubations. 
Figure 5: All BOA-OH isomers elicit weak to strong (shown here) bubble formation in the root hair zones, depending on BOA-OH concentration. 1A: Control, tap water $+500 \mu 1 \mathrm{MeOH}$; $1 \mathrm{~B}$ : BOA-4-OH; 1C: BOA-5-OH; 1D: BOA-6-OH; 1E: BOA-7-OH. Arrow heads point to root hairs with bubbles at their tips and to root hairs of the control seedlings (1A). 2A: $500 \mu \mathrm{M}$ of BOA-6-OH elicited no catalase activity developed during the first hours, arrow points to a white root tip (see gene expression study). 2B: Low catalase activity after $6 \mathrm{~h} ; 2 \mathrm{C}$ : Whole plant to A2; 2D: Control plant. 3A: Sections of collected root surface microorganisms grown on LB agar plates, control; 3B treated with BOA-4-OH; 3C treated with BOA-5-OH; 3D treated with BOA6-OH. Arrows point to large bubbles due to catalase activity.

Figure 6: Total fatty acids in maize roots. Left side: unsaturated fatty acids; Right side saturated fatty acids. A: RTa (young root tissue), B: RTb (older root tissue). RTa und RTb samples were taken without (t0) and after exposure to $0.5 \mathrm{mM}$ BOA-6-OH for 10, 20, 30-, 40-, 50- and 60$\min$. The figure shows mean values and standard deviations $(n=3)$. Significance with reference to t0 (t-test): $* \mathrm{p}<0.05 ; * * \mathrm{p}<0.005 ; * * * \mathrm{p}<0.0005)$.

Figure 7: Total fatty acids in Abutilon root tips. Left side: unsaturated fatty acids; Right side: saturated fatty acids. A: RTa (young root tissue), B: RTb (older root tissue). RTa und RTb samples were taken without (t0) and after exposure to $0.5 \mathrm{mM}$ BOA-6-OH for 10, 20, 30-, 40, 50- and $60 \mathrm{~min}$. The figure shows mean values and standard deviations $(\mathrm{n}=3)$. ). Significance with reference to t0 (t-test): $* \mathrm{p}<0.05 ; * * \mathrm{p}<0.005 ; * * * \mathrm{p}<0.0005)$.

Figure 8: Maize (a:ZmRTa/b:ZmRTb) and Abutilon (a: AbRTa/b:AbRTb). Major structural phospholipids: PC phosphatidylcholine, PE phosphatidylethanolamine, PG phosphatidylglycerol, PI phosphatidylinositol. Glycolipids: MGDG, DGDG. Grouped columns present control and incubation times (left to right: $0=$ control, 10, 20, 30, 40, 50, $60 \mathrm{~min}$ ) of the different glyco/phospholipids. Molecular species are given in Fig. S1. ). Significance with reference to t0 (t-test): $\left.{ }^{*} \mathrm{p}<0.05 ; * * \mathrm{p}<0.005 ; * * * \mathrm{p}<0.0005\right)$.

Figure 9: Maize TAGs: Series ZmRTa: A decrease in many molecular species is found after 20 min, while other species are not affected $(52.5$; 54.3) or increase (54.7). In ZmRTb, the major 
tendency was an increase of many species, although contents varied strongly. Abutilon TAGs: Series AbRTa: A decrease of most of the molecular species is found after 10 min. In AbRTb, the 52. 5-2 molecular species are less affected than the 54.7-3 ones. TAG 54.6 and 54.5 decreased during the first $20 \mathrm{~min}$. Grouped columns present control and incubation times (left to right: $0=$ control, 10, 20, 30, 40, 50, $60 \mathrm{~min})$. ). Significance with reference to t0 (t-test): *p $<0.05 ; * * \mathrm{p}<0.005 ; * * * \mathrm{p}<0.0005)$.

Figure 10: Defined DAGs are significantly affected in Abutilon (Ab) but not in maize $(\mathrm{Zm})$ sample series RTa and RTb. Grouped columns present control and incubation times (left to right: $0=$ control, 10, 20, 30, 40,50, $60 \mathrm{~min}$ ). Molecular species with low abundance (for instance 18:1/18:3 in Abutilon and 16:0/18:1 and 18:1/18:2 in maize are not affected. Significance with reference to t0 (t-test): ${ }^{*} \mathrm{p}<0.05 ; * * \mathrm{p}<0.005 ; * * * \mathrm{p}<0.0005$ ).

Figure 11: Heat map of genes affected by BOA-OH isomers. Relative transcript accumulation for genes encoding enzymes involved ROS detoxification (SOD2; CAT1, CAT3), fatty acid desaturation (FAD2.1; FAD2.2) and genes related to pathogenesis and resistance (PR1, PR2, NPR1, POX12). Responses to BOA-OH isomer exposure are shown for $30 \mathrm{~min}, 1 \mathrm{~h}$ and $6 \mathrm{~h}$ incubation times. Control expression $=0$-fold. The colored bar numbers indicate fold expression compared to the control, colors base on means of three experiments are shown.

Figure 12: A: Contents of detoxification products in maize roots exposed to BOA-OHs for 24 h. HPLC analysis of methanolic extracts from maize roots reveals the accumulation of BOA-6O-glucoside and BOA-5-O-glucoside, but almost no products of BOA-4-OH and BOA-7-OH. B: BOA-6-O-glc accumulation in root tips during the first $h$ of incubation. 
Figures
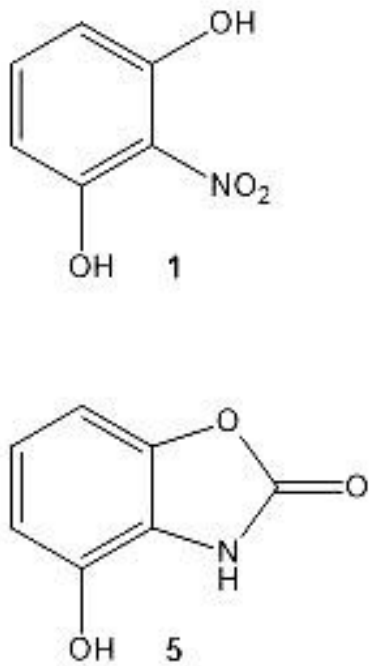
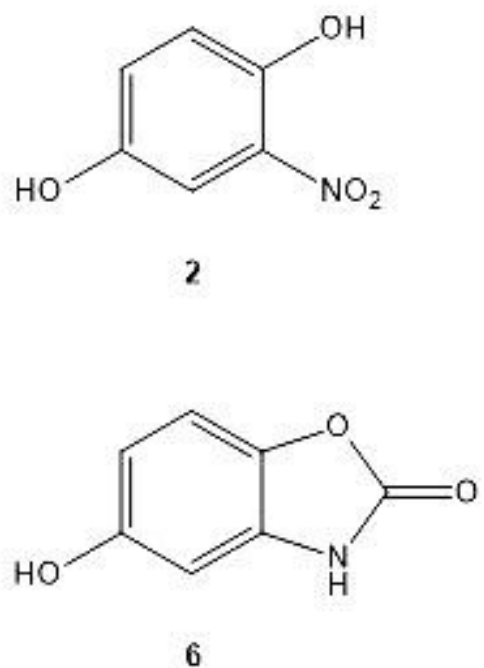<smiles>O=[N+]([O-])c1ccc(O)cc1O</smiles>

3

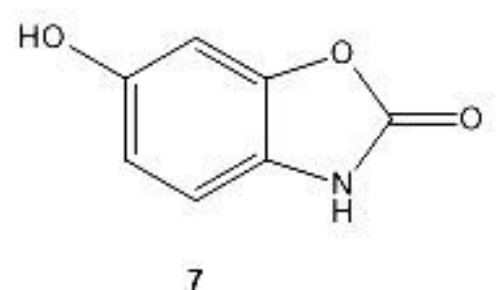<smiles>O=[N+]([O-])c1cccc(O)c1O</smiles>

4<smiles>O=c1[nH]c2cccc(O)c2o1</smiles>

Figure 1

Nitro precursors 1-4 synthesized as precursors for the hydroxy BOAs 5-8. 

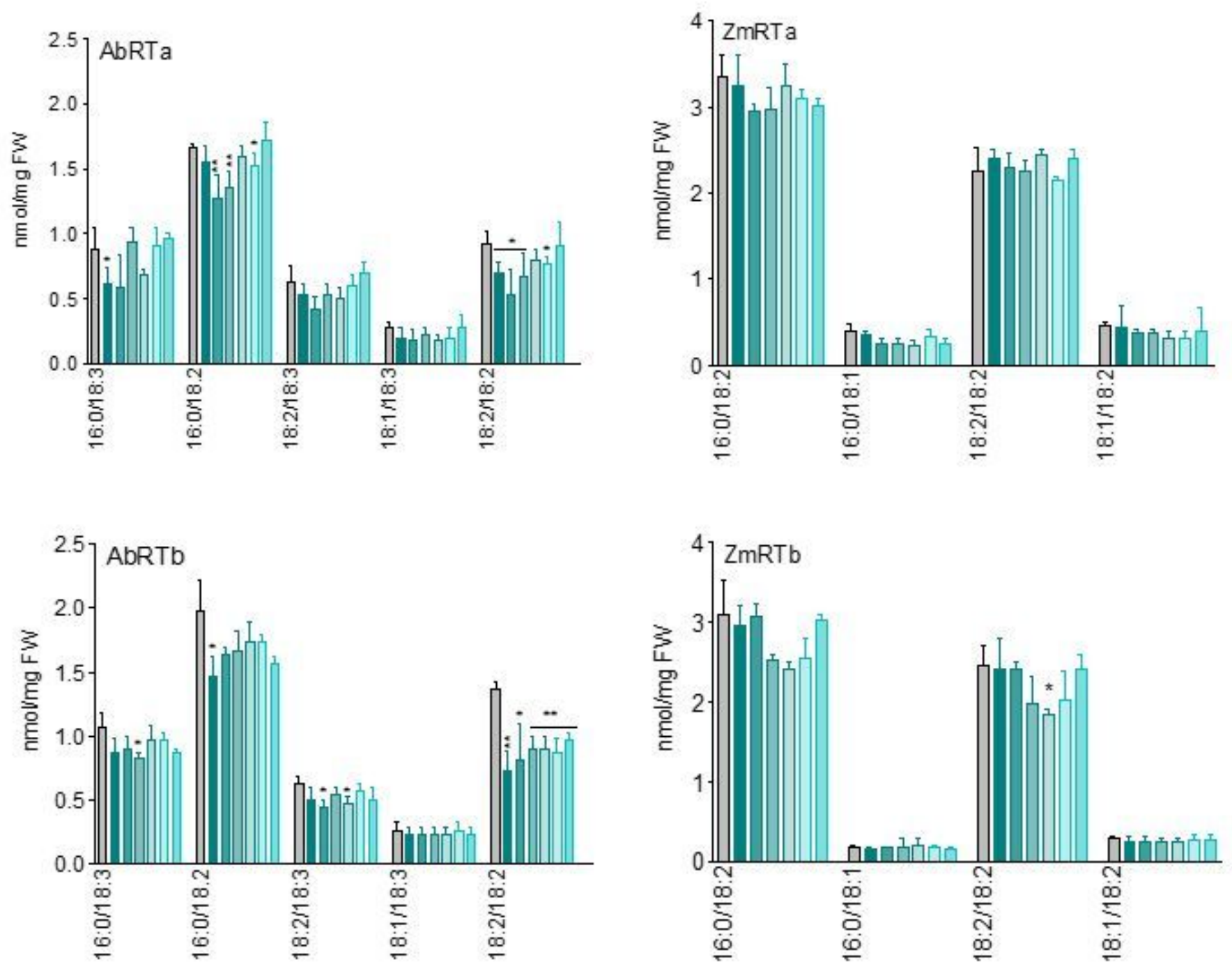

Figure 2

General Synthesis of the four isomeric hydroxy BOAs 5-8. 


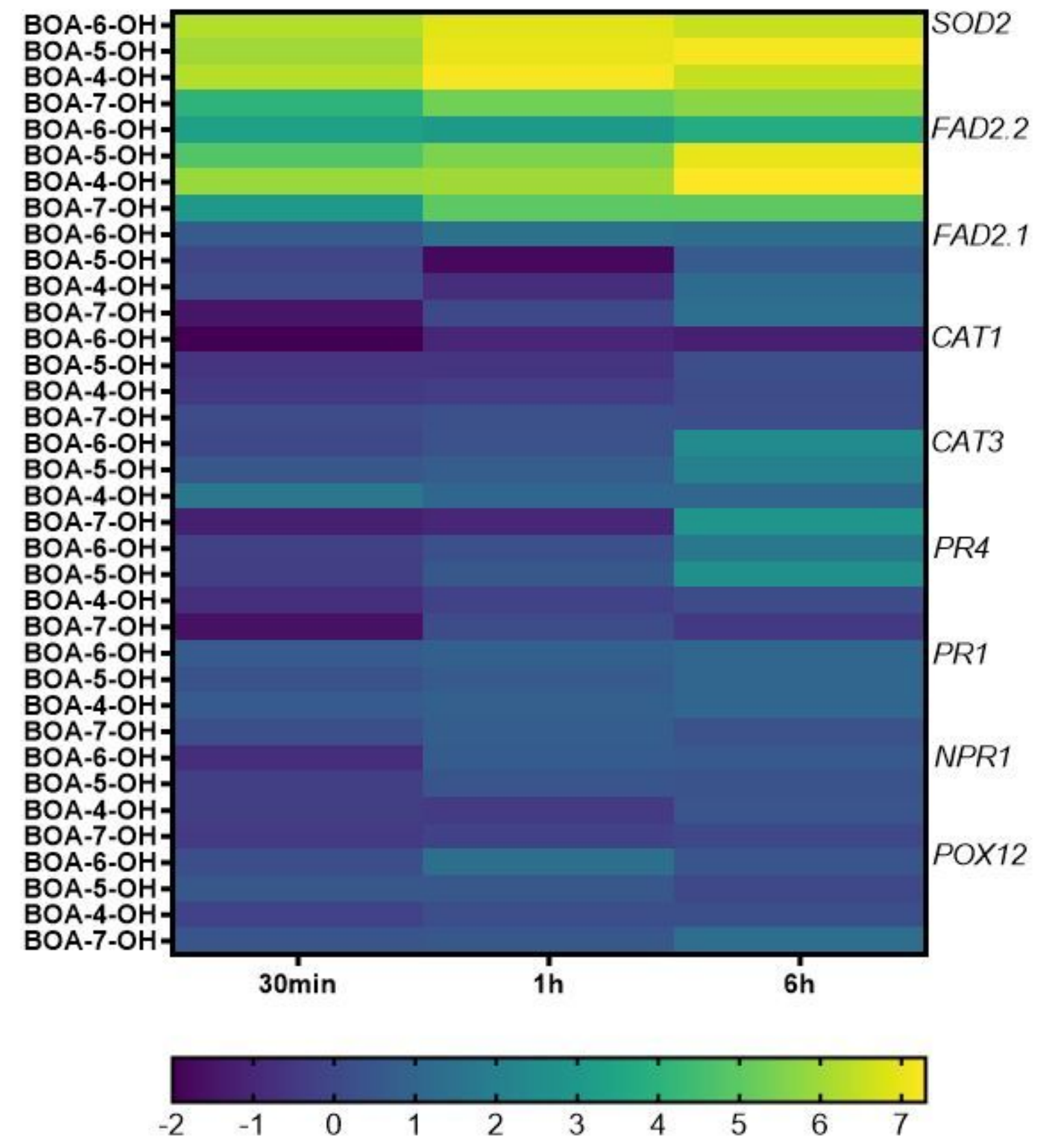

Figure 3

Root hairs $(A)$ were cut and extracted. The extracts and washing solutions obtained from the root hair zone including the mucilage drop $(B)$ were analyzed for benzoxazinoid contents. The extracts of cut root hair contain DIMBOA-glc, DIMBOA and MBOA $(n=12)$, the wash solution only DIMBOA and MBOA $(n=7)$ as major compounds. 

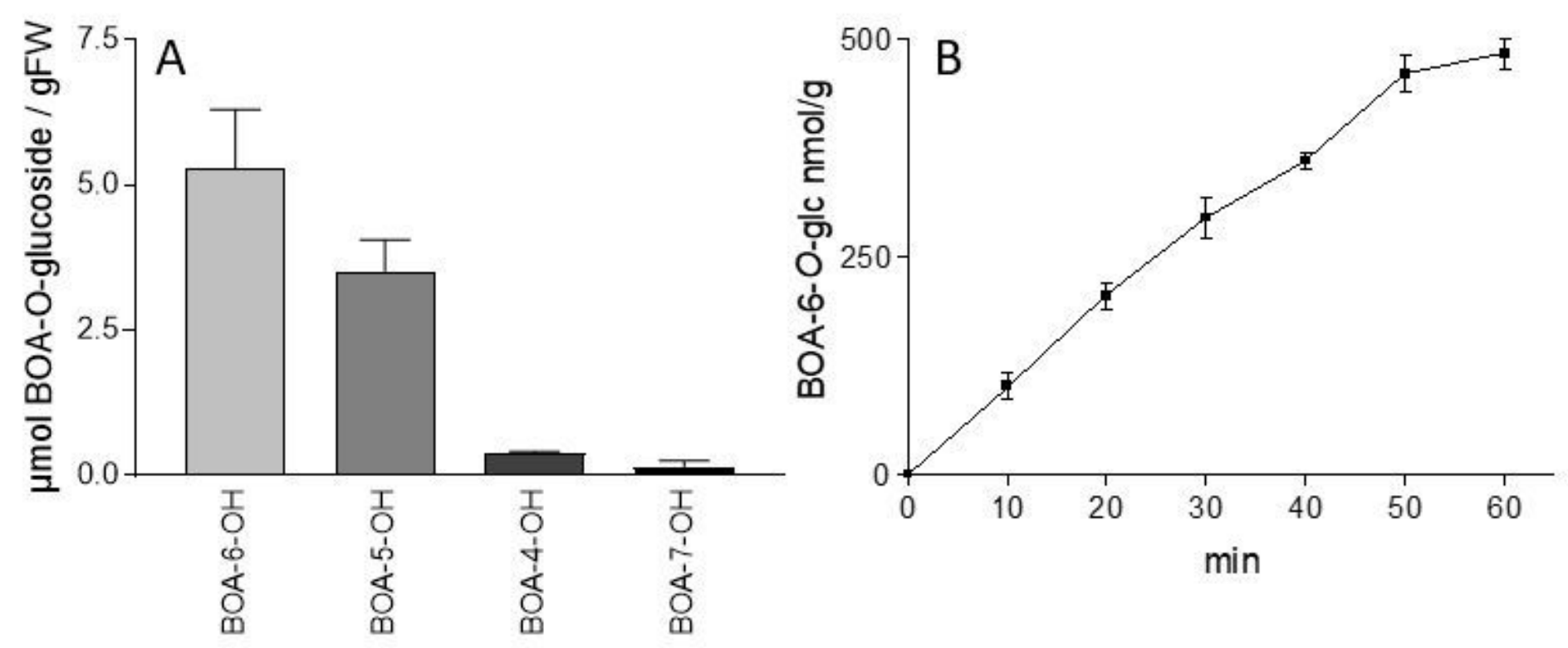

\section{Figure 4}

A, D: Root surface peroxidase assay (ABTS) exposes youngest root zones, the tips covered by the root cap and the bases of emerging roots as sites of peroxidase activity. B: Left to right: control, and after $24 \mathrm{~h}$ incubation with BOA-4-OH, BOA-5-OH, BOA-6-OH, BOA-7-OH.Dark polymers derived from BOA-OHs precipitate at lateral root emerging sites but not at the surface of root hairs, or the tip, C: After BOA-OH incubations, ring-like structures developed preferentially at root zones prior to lateral root emergency. D: Root tips and root caps are dark after assaying peroxidase with ABTS. E: Dark spots at the emerging sites of lateral roots after BOA-OH incubations.

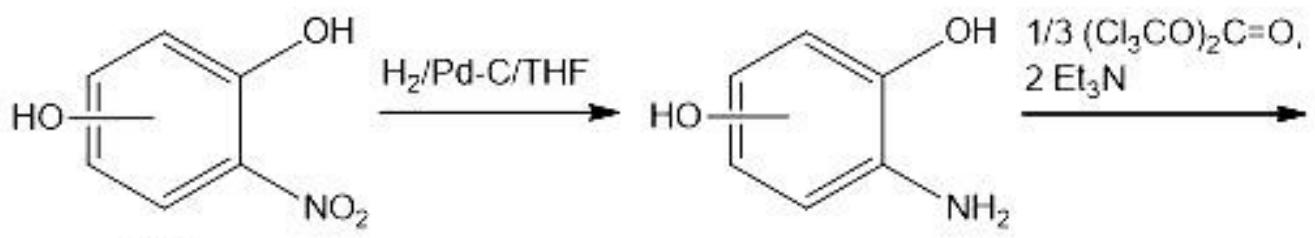

1-4

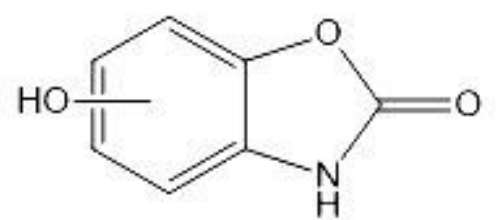

$5-8$

\section{Figure 5}

All BOA-OH isomers elicit weak to strong (shown here) bubble formation in the root hair zones, depending on BOA-OH concentration. 1A: Control, tap water + $500 \mu \mathrm{l} \mathrm{MeOH;} \mathrm{1B:} \mathrm{BOA-4-OH;} \mathrm{1C:} \mathrm{BOA-5-OH;} \mathrm{1D:} \mathrm{BOA-6-}$ $\mathrm{OH} ; 1 \mathrm{E}: \mathrm{BOA}-7-\mathrm{OH}$. Arrow heads point to root hairs with bubbles at their tips and to root hairs of the control seedlings (1A). 2A: $500 \mu \mathrm{M}$ of BOA-6-OH elicited no catalase activity developed during the first hours, arrow points to a white root tip (see gene expression study). 2B: Low catalase activity after 6h; 2C: Whole plant to A2; 2D: Control plant. 3A: Sections of collected root surface microorganisms grown on LB agar plates, control; $3 \mathrm{~B}$ treated with $\mathrm{BOA}-4-\mathrm{OH} ; 3 \mathrm{C}$ treated with $\mathrm{BOA}-5-\mathrm{OH} ; 3 \mathrm{D}$ treated with $\mathrm{BOA}-6-\mathrm{OH}$. Arrows point to large bubbles due to catalase activity. 


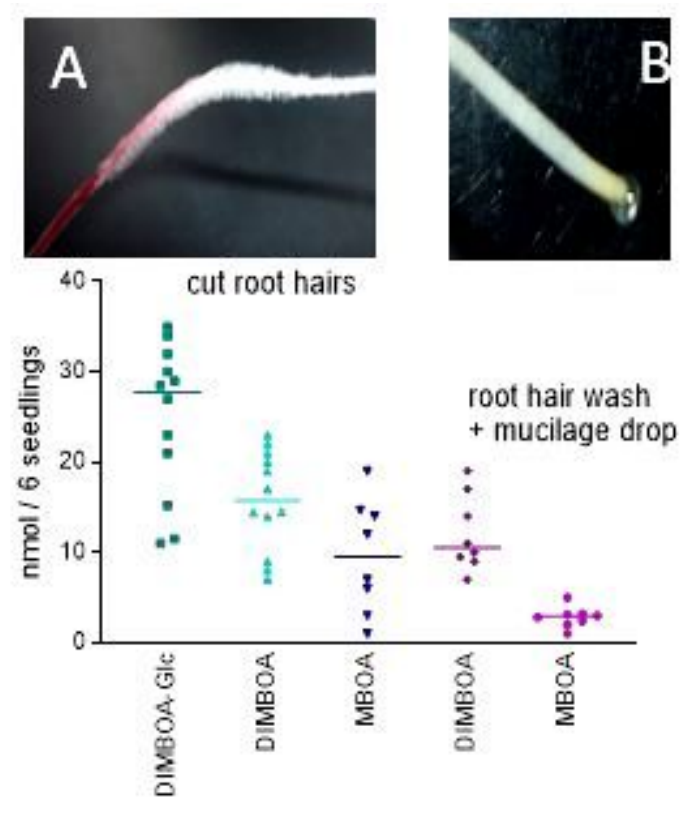

\section{Figure 6}

Totalfatty acids in maize roots. Left side: unsaturated fatty acids; Right side saturated fatty acids. A: RTa (young root tissue), B: RTb (older root tissue). RTa und RTb samples were taken without (t0) and after exposure to $0.5 \mathrm{mM}$ BOA-6-OH for 10, 20, 30-, 40-, 50- and 60-min. The figure shows mean values and standard deviations $(n=3)$. Significancewith reference to t0 (t-test): $\left.{ }^{\star} p<0.05 ;{ }^{*} p<0.005 ;{ }^{* \star} p<0.0005\right)$.

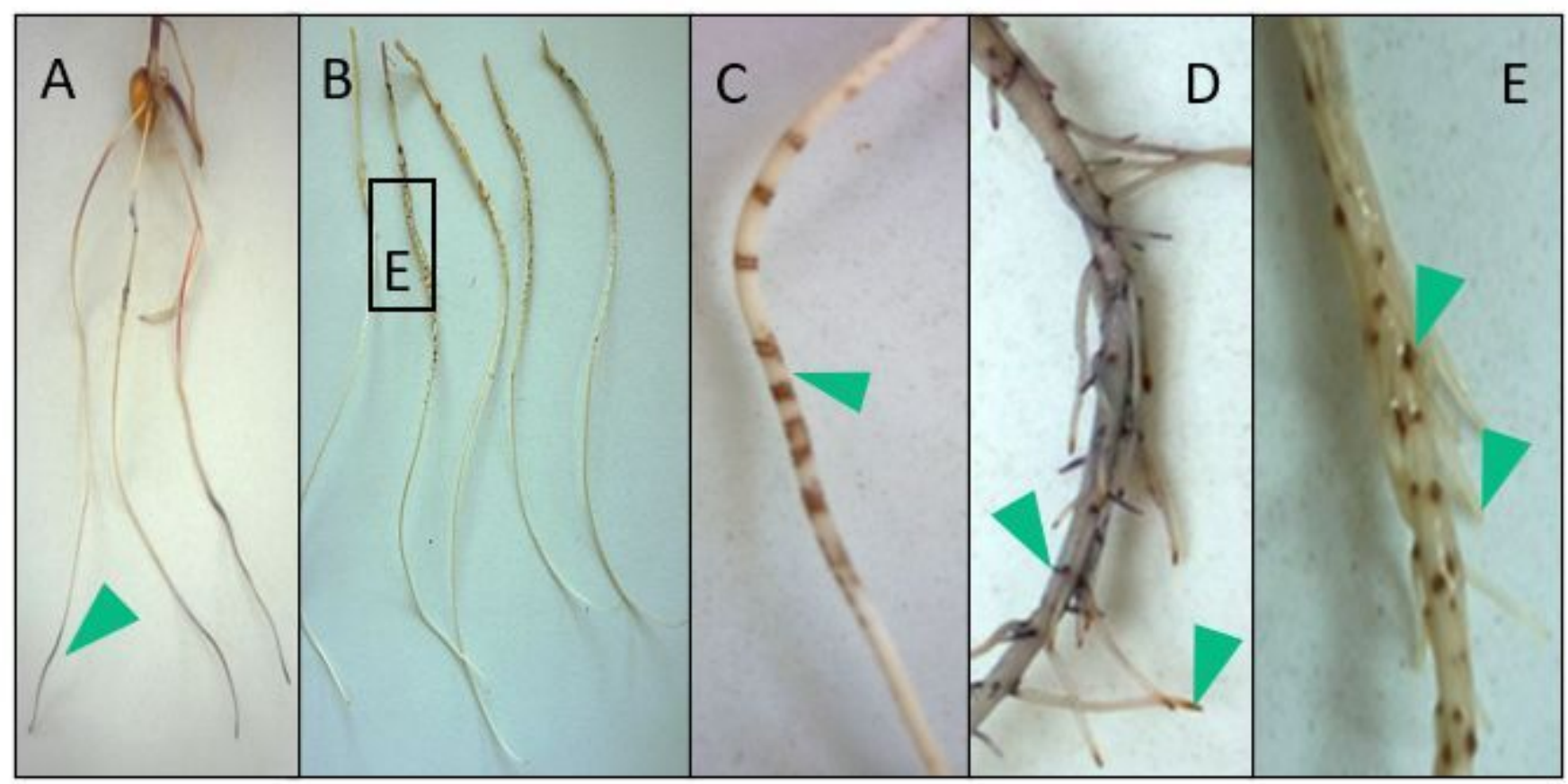

Figure 7

Total fatty acids in Abutilon root tips. Left side: unsaturated fatty acids; Right side: saturated fatty acids. A: RTa (young root tissue), B: RTb (older root tissue). RTa und RTb samples were taken without (t0) and after exposure to $0.5 \mathrm{mM} \mathrm{BOA-6-OH}$ for $10,20,30-, 40-, 50$ - and $60 \mathrm{~min}$. The figure shows mean values 
and standard deviations $(n=3)$.). Significance with reference to t0 (t-test): ${ }^{\star} p<0.05 ;{ }^{\star \star} p<0.005 ; * \star * p<$ 0.0005).
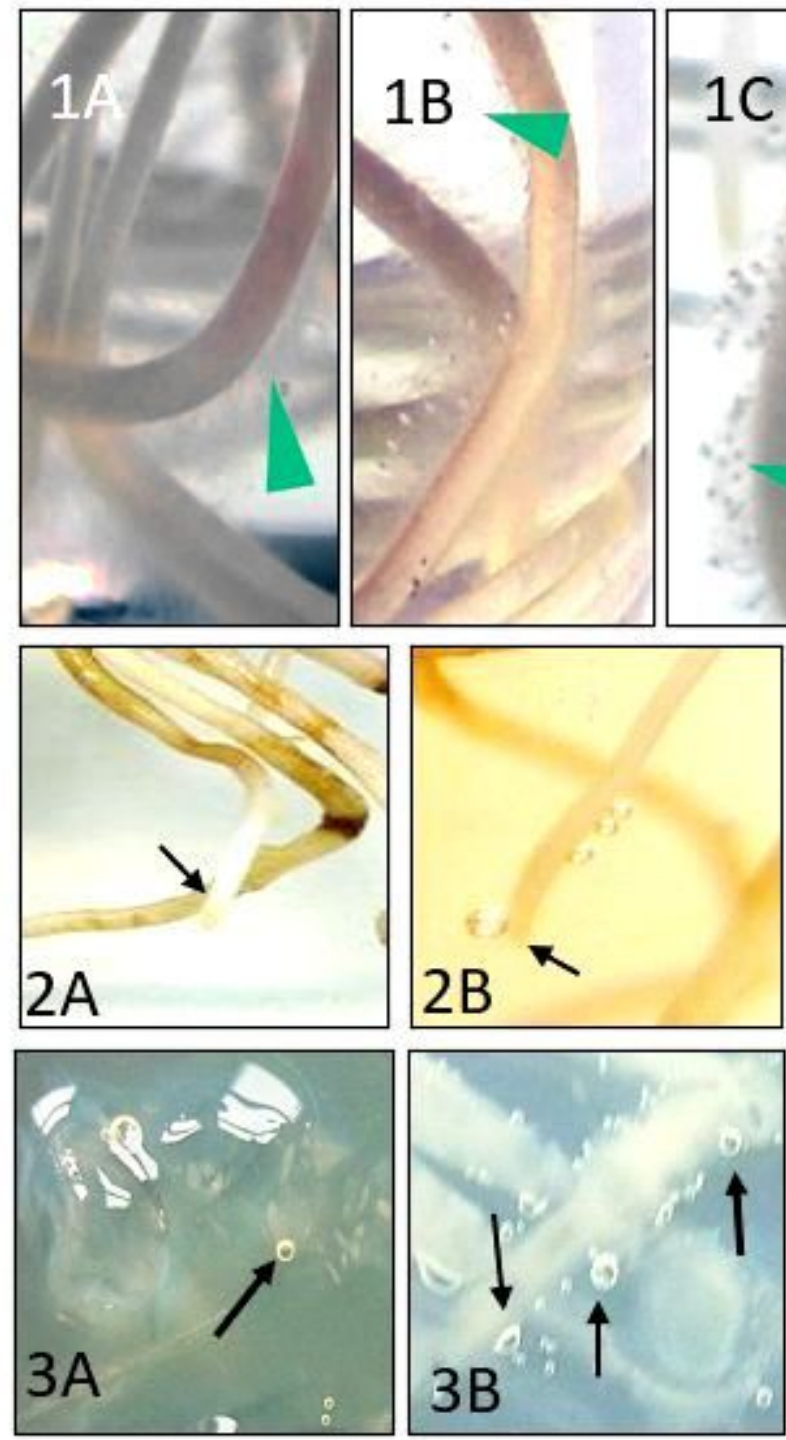
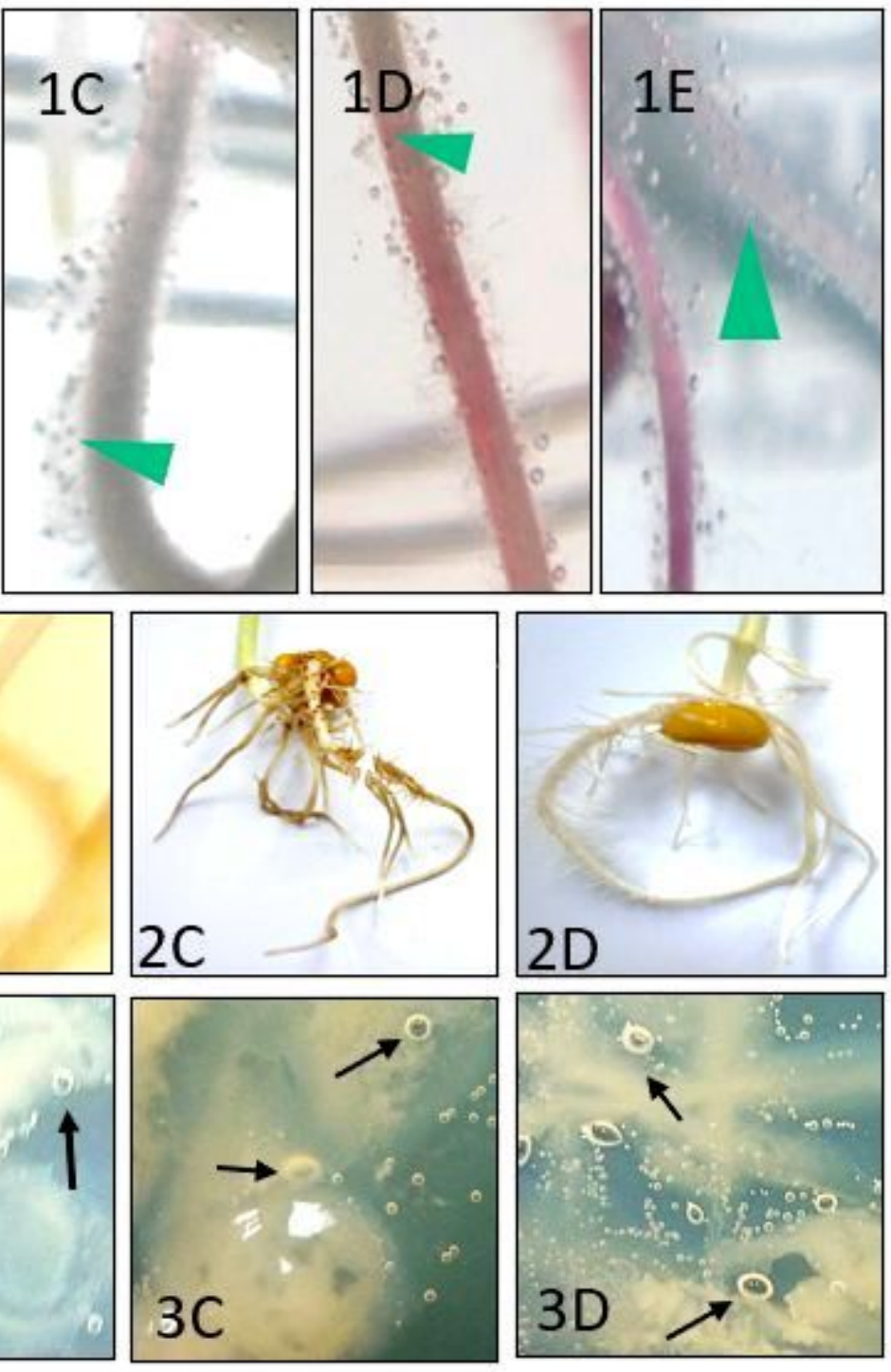

\section{Figure 8}

Maize (a:ZmRTa/b:ZmRTb) and Abutilon (a: AbRTa/b:AbRTb). Major structural phospholipids: PC phosphatidylcholine, PE phosphatidylethanolamine, PG phosphatidylglycerol, PI phosphatidylinositol. Glycolipids: MGDG, DGDG. Grouped columns present control and incubation times (left to right: $0=$ control, 10, 20, 30, 40, 50, $60 \mathrm{~min}$ ) of the different glyco/phospholipids. Molecular species are given in Fig. S1.). Significancewith reference to t0 (t-test): ${ }^{*} p<0.05 ;{ }^{* \star p}<0.005 ; * \star * p<0.0005$ ). 

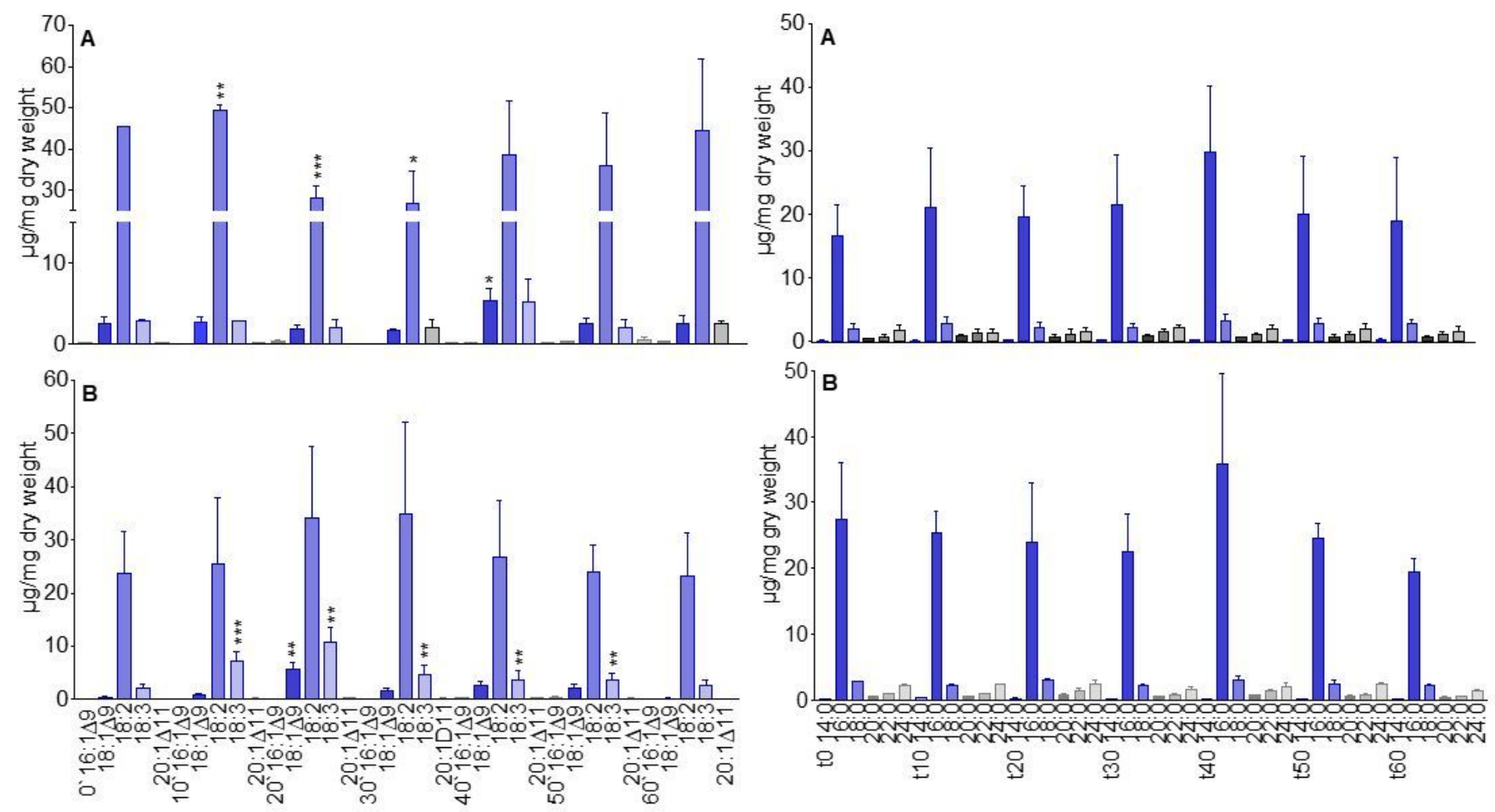

Figure 9

Maize TAGs: Series ZmRTa: A decrease in many molecular species is found after 20 min, while other species are not affected $(52.5 ; 54.3)$ or increase (54.7). In ZmRTb, the major tendency was an increase of many species, although contents varied strongly. Abutilon TAGs: Series AbRTa: A decrease of most of the molecular species is found after $10 \mathrm{~min}$. In AbRTb, the 52. 5-2 molecular species are less affected than the 54.7-3 ones. TAG 54.6 and 54.5 decreased during the first 20 min. Grouped columns present control and incubation times (left to right: $0=$ control, 10, 20, 30, 40, 50, $60 \mathrm{~min}$ ).). Significance with reference to t0 (t-test): ${ }^{\star} \mathrm{p}<0.05 ;{ }^{* \star} \mathrm{p}<0.005 ; * \star \star \mathrm{p}<0.0005$ ). 

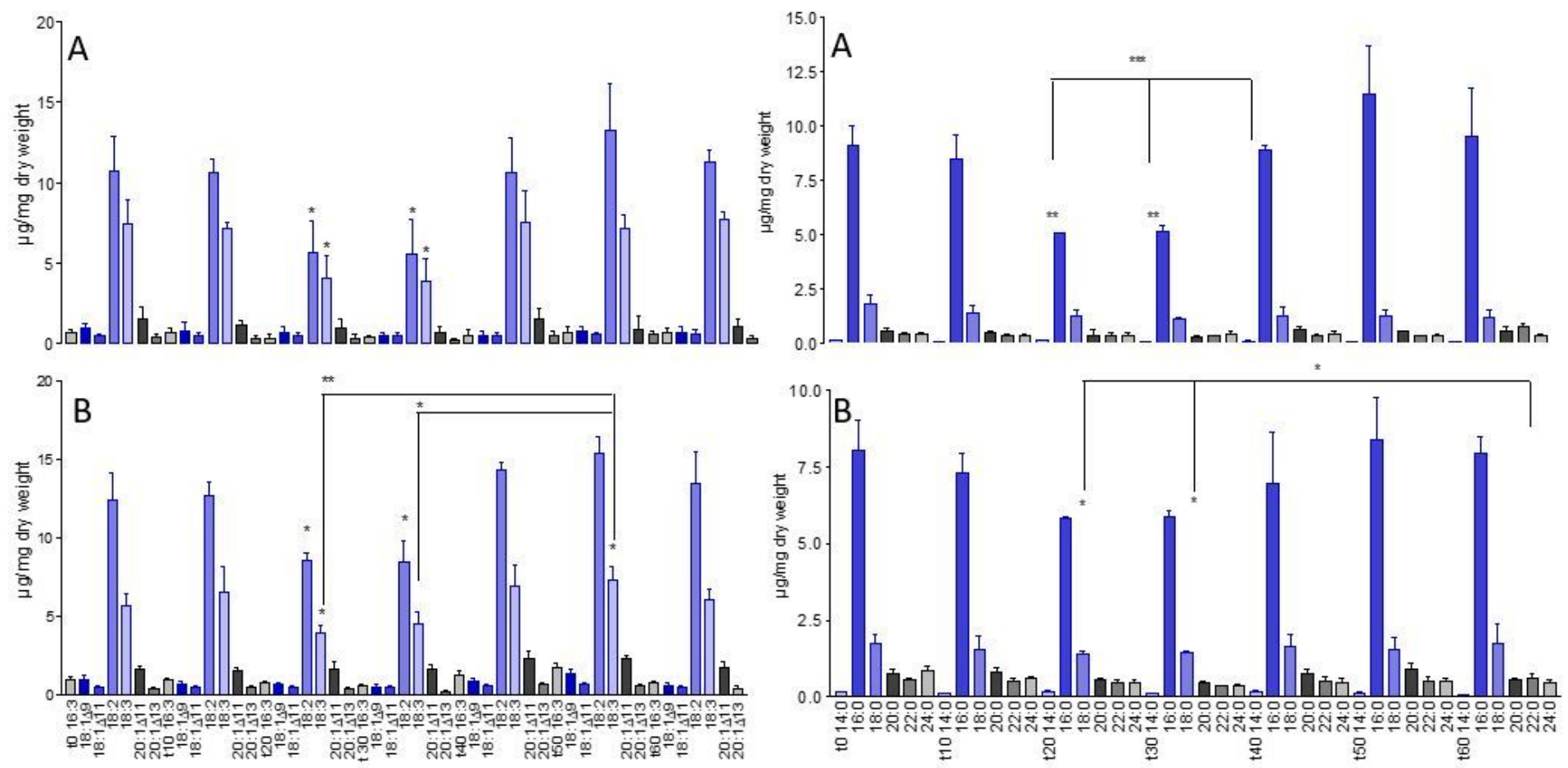

Figure 10

Defined DAGs are significantly affected in Abutilon (Ab) but not in maize $(\mathrm{Zm})$ sample series RTa and RTb. Grouped columns present control and incubation times (left to right: $0=$ control, 10, 20, 30, 40, 50, 60 min). Molecular species with low abundance (for instance 18:1/18:3 in Abutilon and 16:0/18:1 and 18:1/18:2 in maize are not affected.Significance with reference to t0 (t-test): ${ }^{*} p<0.05$; ${ }^{\star \star} p<0.005$; $* \star x p<$ $0.0005)$. 

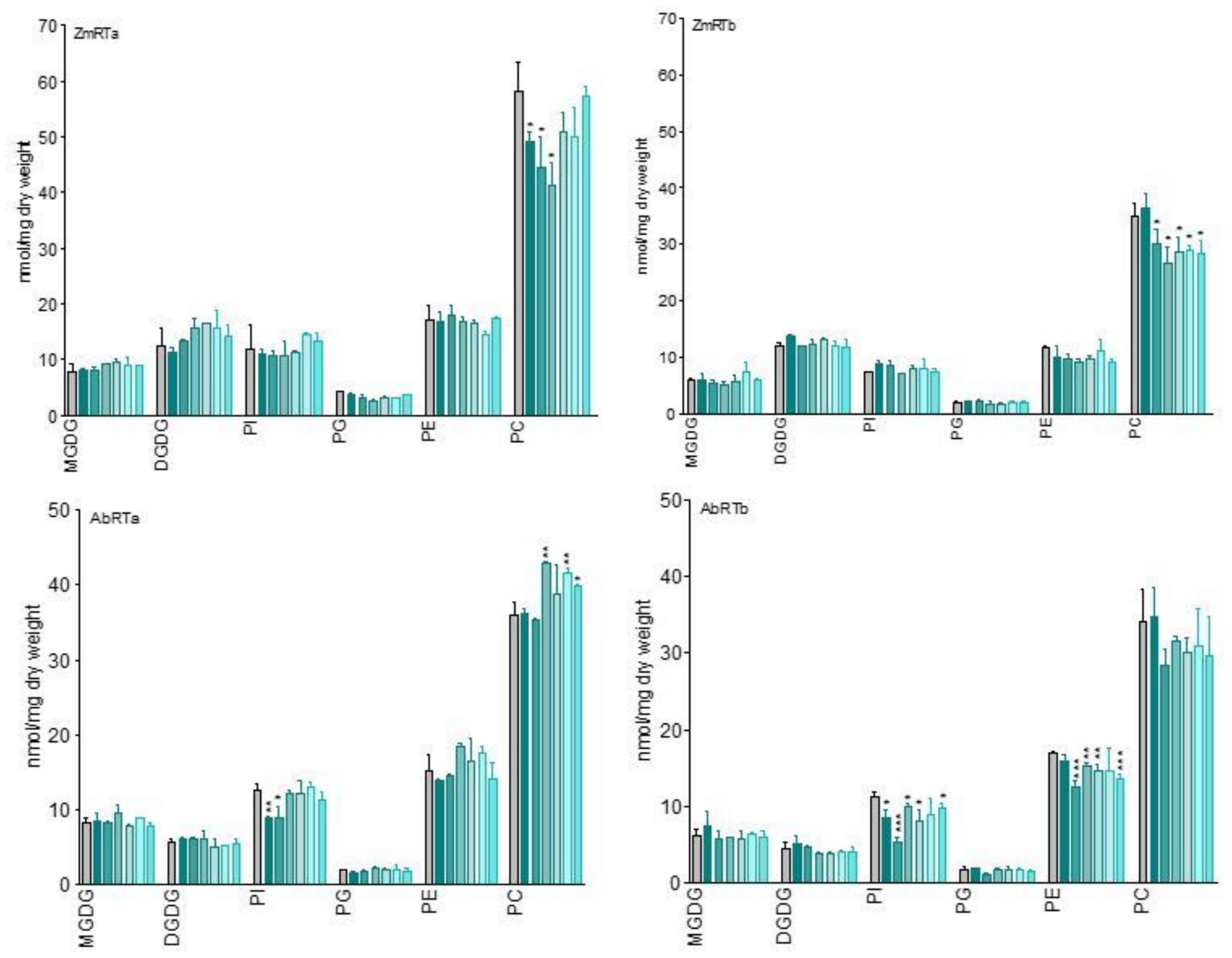

Figure 11

Heat map of genes affected by BOA-OH isomers. Relative transcript accumulation for genes encoding enzymes involved ROS detoxification (SOD2; CAT1, CAT3), fatty acid desaturation (FAD2.1; FAD2.2) and genes related to pathogenesis and resistance (PR1, PR2, NPR1, POX12). Responses to BOA-OH isomer exposure are shown for $30 \mathrm{~min}, 1 \mathrm{~h}$ and $6 \mathrm{~h}$ incubation times. Control expression $=0$-fold. The colored bar numbers indicate fold expression compared to the control, colors base on means of three experiments are shown. 

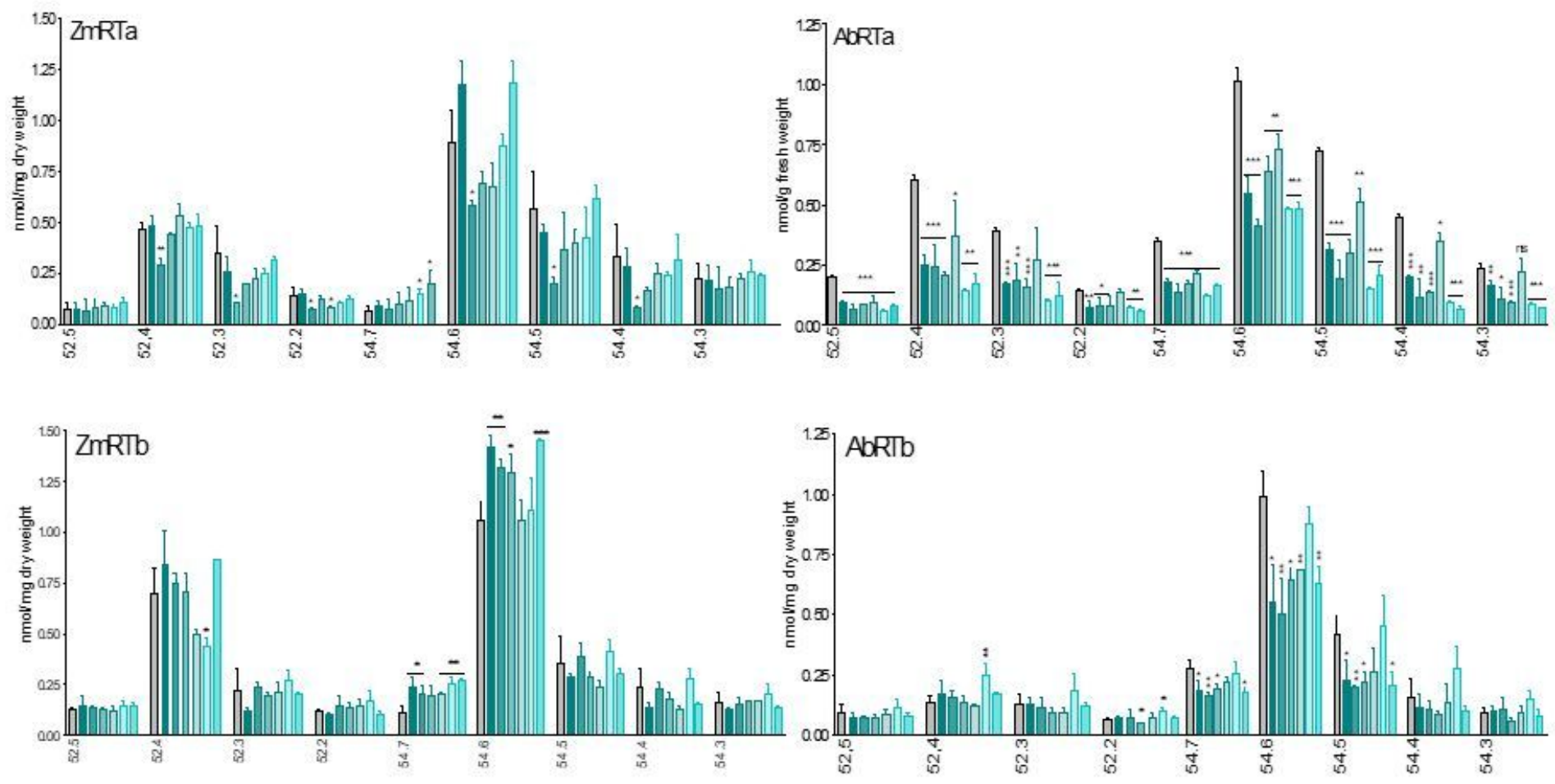

Figure 12

A: Contents of detoxification products in maize roots exposed to BOA-OHs for $24 \mathrm{~h}$. HPLC analysis of methanolic extracts from maize roots reveals the accumulation of BOA-6-O-glucoside and BOA-5-Oglucoside, but almost no products of $\mathrm{BOA}-4-\mathrm{OH}$ and $\mathrm{BOA}-7-\mathrm{OH}$. B: BOA-6-0-glc accumulation in root tips during the first $h$ of incubation.

\section{Supplementary Files}

This is a list of supplementary files associated with this preprint. Click to download.

- Supplementarylnformation.pdf 